PARENTAL PREFERENCES AND SCHOOL COMPETITION: EVIDENCE FROM A PUBLIC SCHOOL CHOICE PROGRAM

Justine S. Hastings

Thomas J. Kane

Douglas O. Staiger

Working Paper 11805 
NBER WORKING PAPER SERIES

\title{
PARENTAL PREFERENCES AND SCHOOL COMPETITION: EVIDENCE FROM A PUBLIC SCHOOL CHOICE PROGRAM
}

\author{
Justine S. Hastings \\ Thomas J. Kane \\ Douglas O. Staiger \\ Working Paper 11805 \\ http://www.nber.org/papers/w11805 \\ NATIONAL BUREAU OF ECONOMIC RESEARCH \\ 1050 Massachusetts Avenue \\ Cambridge, MA 02138 \\ November 2005
}

We thank the Charlotte-Mecklenburg School Board, Office of the Superintendent, as well as the excellent school district staff for making this project possible. We would also like to thank Joseph Altonji, Patrick Bayer, Steven Berry, Philip Haile, Fabian Lange, Sharon Oster, Miguel Villas-Boas, Sofia Villas-Boas, and seminar participants at Yale University, University of California at Berkeley, and University of Chicago for helpful comments. We gratefully acknowledge Sean Hundtofte, Jeffrey Weinstein, and Orkun Sahmali for providing outstanding research assistance. The project is funded by grants from the Institution for Social and Policy Studies at Yale University and the U.S. Department of Education. The views expressed herein are those of the author(s) and do not necessarily reflect the views of the National Bureau of Economic Research.

(C2005 by Justine S. Hastings, Thomas J. Kane, and Douglas O. Staiger. All rights reserved. Short sections of text, not to exceed two paragraphs, may be quoted without explicit permission provided that full credit, including (C) notice, is given to the source. 
Parental Preferences and School Competition: Evidence from a Public School Choice Program Justine S. Hastings, Thomas J. Kane, and Douglas O. Staiger

NBER Working Paper No. 11805

November 2005, Revised December 2006

JEL No. I0, I20, I28

\begin{abstract}
This paper uses school choice data from the Charlotte-Mecklenburg School District to study parents' preferences for school characteristics and their implications for demand and competition in school choice. We estimate a mixed-logit demand model using the rankings of parents' top three school choices in the first year of school choice. Our results show that parents value proximity highly and preferences for school test scores increase with student income and own academic ability. We also find considerable heterogeneity in idiosyncratic preferences, with negative correlations between preferences for academics and proximity. Unique aspects of the choice plan, such as the redrawing of school boundaries, allow us to test for bias from endogenous residential location and strategic choices. Simulations of parental responses to school test score improvements suggest that the demand response at high-performing schools would be larger than at low-performing schools, leading to disparate demand-side pressure to improve performance under school choice.

Justine S. Hastings

Yale University Department of Economics

P.O. Box 20868

New Haven, CT 06520

and NBER

justine.hastings@yale.edu

Thomas J. Kane

Harvard University

Graduate School of Education

Gutman Hall 455

Cambridge, MA 02138

and NBER

kaneto@gse.harvard.edu

Department of Economics 6106 Rockefeller Hall Hanover, NH 03755 and NBER douglas.staiger@dartmouth.edu
\end{abstract}

Douglas O. Staiger

Dartmouth College 


\section{Introduction}

School choice plans are intended to improve both education quality and equity by providing demand-side incentives for schools to compete for students and by allowing broader access to quality public schools. Urban public school districts, such as those in Charlotte, Milwaukee and Washington DC, are currently experimenting with ways to promote greater competition, such as public school choice plans, charter school programs, and limited voucher plans. Moreover, the recent federal No Child Left Behind Act (NCLB) requires districts receiving federal Title I funds to allow students in failing schools to choose to attend non-failing schools outside of their neighborhood.

However, theory suggests that the potential effect of expanded choice depends critically on the distribution of consumer preferences for product (school) characteristics (Anderson, de Palma and Thisse (1992)). For example, if parents care primarily about proximity and convenience, then schools may not face much pressure to improve under school choice. On the other hand, if parents choose schools primarily for academic achievement, then school choice may lead to intense pressure to improve education quality, leading to overall academic gains ('a tide that lifts all boats'). Differences in preferences across socio-economic groups can also have important consequences. If highincome families and parents of high-achieving students focus on academics when choosing schools, while low-income families focus on proximity or convenience, then schools may become more stratified under school choice. Strong academic schools may compete in a city-wide market for higher-achieving students while schools in low-income neighborhoods serve the remaining students, acting as 'local monopolists' with little pressure to improve.

The ultimate impact of greater parental choice depends upon the nature of parental preferences. However, econometric evidence on parental preferences and the effects of school choice on overall academic achievement is quite limited. In the absence of micro data with which to directly estimate the demand for schools, researchers in the related literature have been forced to make strong assumptions about the nature of demand and competition. For instance, researchers have recently focused on the relationship between measures of district 'concentration' (HHI) across metropolitan areas 
and average student achievement (Borland and Howson (1992), Hoxby (2000), Hanushek and Rivkin (2003), Belfield and Levin (2002)). However, the relationship between the $\mathrm{HHI}$ and the degree of competition rests on certain assumptions regarding the nature of demand and market structure, namely that firms (here schools or districts) are symmetric and compete on quantity in a homogeneous goods market (Farrell and Shapiro (1990)). The results of this literature are mixed (Belfield and Levin (2002)), with significant positive, negative and insignificant relationships between measures of student achievement and measures of market concentration. Another related literature has taken a theoretical approach, using computable general equilibrium models to simulate the impact of stylized choice programs on student sorting and achievement (Nechyba (1999, 2000, 2003), and Epple and Romano (1998, 2002)). These models allow for comparisons of alternative hypothetical choice programs, but must make assumptions regarding parental preferences with little empirical guidance.

In this paper, we use a unique natural experiment in the Charlotte-Mecklenburg School district (CMS), in North Carolina, to estimate the distribution of preferences for key school characteristics. We use multiple ranked data from parents' school choices for the first year of district-wide school choice to estimate a mixed-logit model of demand for schools, allowing preferences to vary idiosyncratically as well as with observed characteristics such as race, income, and baseline academic achievement. We find that preferences for measures of academic quality are increasing in income and student baseline achievement. We also find that parents highly value proximity, but that idiosyncratic preferences for measures of academic achievement and proximity are negatively correlated, implying that parents with strong preferences for academic achievement are willing to leave their local neighborhood to get it. We use these preference distributions to simulate the demand-side response to an increase in a school's mean test score, all else equal. We find that higher performing schools compete for elastic students and experience a relatively high demand response to an incremental improvement in mean test scores. Lower performing schools, however, face little demand-side pressure to improve, serving mostly local, inelastic families. Such results suggest that public school choice may lead towards greater educational stratification of schools serving high and low income youth. 
Several aspects of the Mecklenburg County choice plan make it ideal for estimating demand parameters. First, CMS introduced public school choice in the fall of 2002, after a race-based bussing plan was terminated by court order. Under the choice plan, parents in the district were asked to submit their top three choices of schools for their children. Approximately 95\% of the 110,000 students submitted choices for the choice plan. Thus we have data for nearly the entire student population-whereas most work using school choice data has been dependent on limited and potentially nonrepresentative subgroups of students. Second, the multiple responses create variation in the choice set by effectively removing the prior chosen school from the subsequent choice set. This choice-set variation allows us to estimate the distribution of preferences for school characteristics from observed substitution patterns for each individual - a stronger source of variation for identification than cross-sectional changes in the choice set based on geographic location (Berry, Levinsohn, and Pakes (2004)). Third, historic placement of schools for busing in CMS provides wide variation in school characteristics for families in all socio-economic groups, dampening collinearity problems that may be present in other settings.

Moreover, the introductory year of the school choice plan provides a unique opportunity to test for the importance of potentially confounding factors such as residential sorting and strategic behavior. First, the district redrew school boundaries when they implemented the school choice plan. As a result, approximately fifty percent of families lost property rights to the school they would have been guaranteed to attend the year before. This exogenous shock to residential sorting helps identify preferences for proximity from preferences for other school characteristics. Second, the redrawing of school boundaries allows us to test for the presence of strategic behavior. Had parents known the school assignment mechanism, some may have had an incentive to misrepresent their true preferences. Given the way slots in oversubscribed schools were allocated, those with weaker default schools would have had an incentive to "hedge" their first choices, by listing a less popular school first (Glazerman and Meyer (1994), Abdulkadiroglu and Sonmez (2003)). We test whether choices were different for those reassigned to stronger and weaker schools. We find little evidence of such strategizing in the first year of the program, although participants could develop such strategic behavior 
as they become more familiar with the choice system and they learn more about which choices will be oversubscribed (Roth and Erev (1995), Kagel and Roth(2000)).

In the absence of public school choice, residential location alone determines school assignment. Public school choice advocates argue that competition on the basis of residential location alone may be not be enough to spur schools to focus on student achievement, since parental responses are muted by budget constraints and desires for other neighborhood attributes. Our results measure the additional competitive pressure created by a public school choice plan when school assignments are decoupled from residential location. Our analysis points to heterogeneous preferences in a differentiated schools (products) market and the resulting market segmentation as key factors limiting competition among schools even after geographic-based constraints are lifted.

\section{Previous Literature on School Choice and Competition}

In recent years, a number of papers have estimated the impact of market “concentration” in local public schools on educational outcomes. (Borland and Howson (1992), Hoxby (2000), Hanushek and Rivkin (2003)). Belfield and Levin (2002) provide a thorough review of this extensive literature. Without micro data with which to directly estimate demand for schools, researchers often assume that competition in the schooling market in a metropolitan area can be measured by an HHI (Herfindahl-Hirschman Index) of districts. The higher the concentration of districts, the lower the extent of competition, and the lower the pressure to improve academically should be. However, the relationship between $\mathrm{HHI}$ and competition is derived mechanically from the equilibrium price-cost margins in an n-firm symmetric Cournot model of competition (Farrell and Shapiro (1990)). The use of the HHI itself takes as a premise certain assumptions on product differentiation and preferences. ${ }^{1}$ Therefore, such studies provide no test for differential demand-side pressures across schools serving different socio-economic classes. Neither

\footnotetext{
${ }^{1}$ Recognizing that, outside of the symmetric firm Cournot model, the HHI is no longer a sufficient statistic for competition, the recent literature in industrial organization has focused on estimating underlying preference parameters of consumer's indirect utility to understand demand, substitution patterns, and nature of competition between firms in differentiated products markets. In our context, estimates of preference parameters will yield estimates of the demand response faced by individual schools, allowing insights into the nature of competitive pressure on quality and student sorting under school choice.
} 
can such studies shed light on student sorting (which types of students will pick which schools), test which schools compete for which students, or elucidate effective supplyside policy to increase demand-elasticity or improve educational equity. The results of this literature are mixed, with negative, positive, and insignificant relationships between HHI's and educational outcomes (Belfield \& Levin (2002), Table 1).

Other researchers have explored theoretical models of student sorting and equilibrium outcomes under various forms of voucher plans (Nechyba (1999, 2000, 2003), and Epple and Romano $(1998,2002)){ }^{2}$ The general equilibrium approach has the benefit of being able to compare alternative, hypothetical school choice and voucher plans with various funding, admissions, or targeting rules. However, instead of uncovering parental preferences, these models place theoretical assumptions on parental choice behavior in order to compute equilibrium outcomes. For instance, they often assume that preferences are homogeneous or that parents care only about test performance and peer characteristics (and not proximity). In this paper, we will not be able to compare equilibrium outcomes across alternative school choice mechanisms; however we use a large-scale public school choice experiment and parents’ actual choices to uncover preference distributions for school characteristics. The estimates of demand parameters presented in this paper, therefore, should be helpful to future efforts to calculate equilibrium outcomes under alternative school choice mechanisms.

Another set of research papers have focused on survey analysis, studying what parents say they look for when choosing schools. Parents generally state that academic achievement and teacher quality are the most important school characteristics (Armor and Peiser (1998), Vanourek et al. (1998), Greene et al. (1998), Kleitz et al. (2000), Schneider et al. (1998)). However, inferring parents’ preferences from survey responses may not give an accurate estimate of parents' true preferences. For example, parents' stated preferences may be altered to fit social norms - emphasizing a high value for education quality, a low value for convenience, and potentially downplaying concerns for school racial composition. ${ }^{3}$ Furthermore, when responding to hypothetical questions, parents

\footnotetext{
${ }^{2}$ See Neal (2002) for a summary of the results from this literature.

${ }^{3}$ For example, survey research in Political Science often asks people about their voting history. Voting history is verifiable using publicly available voting records. Researchers systematically find that a large
} 
may make assumptions that affect their responses in ways not apparent to the researcher (e.g. automatically incorporating the importance of proximity in their response and implicitly limiting their choice set to nearby schools).

A smaller set of studies have exploited the actual choices parents make to infer parental preferences. ${ }^{4}$ Bayer, Ferreira and McMillan (2003) use actual household location decisions from the US Census to estimate household preferences over a broad range of housing, neighborhood and school characteristics. They find evidence of differences in preferences for neighborhood attributes across observable characteristics. These studies must rely on cross-sectional residential location data to infer preferences for many different neighborhood, school, and life-style characteristics. Glazerman (1997), using a conditional logit framework and data from a limited choice program in Minneapolis, found that while test scores mattered in driving parental choices, parents tended to avoid schools in which their children's racial group represented less than 20 percent of all students. However, the Minneapolis choice plan was a long-standing program that involved only a small percentage of parents with very limited school options, and a history of incentives and participation that may have affected parents stated choices.

In summary, the CMS school choice plan provides a unique opportunity to examine preferences across the population of students at the introduction of a school choice program. The policy experiment and multiple ranked choice data will allow us to overcome hurdles of strategy and residential sorting, and use a more flexible mixed-logit discrete choice framework to estimate both observable and unobservable heterogeneity in preferences (Hausman and Wise (1978) and Berry, Levinsohn, and Pakes (1995, 2004)). We can then use the distribution of preferences to simulate the implications for demandside pressures to improve academic achievement in public school choice.

\section{Details of Public School Choice Plan in CMS}

Before the introduction of a school choice plan in the fall of 2002, the CharlotteMecklenburg public school district (CMS) operated under a racial desegregation order for

fraction of respondents claim that they have voted when in fact they have not. It appears they may do so to conform to social norms (Karp and Brockington (2005)).

${ }^{4}$ See Manski and Wise (1983) for an early application to college choice. 
three decades. In September 2001, the U.S. Fourth Circuit Court of Appeals declared the school district "unitary” and ordered the district to dismantle the race-based student assignment plan by the beginning of the next school year. In December of 2001, the school board voted to approve a new district-wide public school choice plan.

In the spring of 2002, parents were asked to submit their top three choices of school programs for each child. Each student was assigned a "home school" in their neighborhood, often the closest school to them, and was guaranteed a seat at this school. Magnet students were similarly guaranteed admission to continue in their current magnet programs. Admission for all other students was limited by grade-specific capacity limits set by the district. Students could choose any school in the district, however, busing transportation was only guaranteed to schools in a student's quadrant of the district (the district was split into 4 quadrants called 'choice zones'). The district allowed significant increases in school enrollment size in the first year of the school choice program in an expressed effort to give each child one of their top three choices. In the spring of 2002, the district received choice applications for approximately 105,000 of 110,000 students. Approximately 95\% of parents received admission to one of their top three choices. Admission to over-subscribed schools was determined by a lottery system as described below.

\section{Potential for Strategic Choice}

The lottery mechanism used by the Charlotte-Mecklenburg schools was a 'firstchoice-maximizer,' in which slots were first assigned to all those listing a given school as a first choice before moving to those listing the school as a second or third choice. In such a mechanism, parents with poor home school options may have an incentive to misstate their preferences - not listing their most preferred school if it had a low probability of admission (Glazerman and Meyer (1994), Abdulkadiroglu and Sonmez (2003), Abdulkadiroglu et. al (2006)). Instead, they may have hedged their bets by listing a less preferred option with a higher probability of admission in order to avoid being assigned to their home school. Such strategic behavior would imply that student choices would not reflect true preference orderings for schools - to the extent that students are not listing their preferred match due to strategic hedging on quality. 
However, there were a number of reasons why such strategic behavior was unlikely to have been a major concern in the 2002-2003 CMS choice plan. First, parents did not know how the lottery system would be operated. The handful of district officials who knew the lottery details were not allowed to communicate them to parents. Parents were never given their actual lottery numbers. The district also told parents that they would make every attempt to give each student admission to one of their chosen schools, and instructed them to list what they wanted. In order to accommodate demand, the district substantially expanded capacity at popular schools. In addition, the district gave a 'priority boost' to low-income students choosing to attend schools with low concentrations of low income students. Hence, choices for top schools by students with under-performing home schools would be given top priority. This would counteract the incentive for these students to hedge their choices as outlined above.

In addition to these strong a priori reasons to suspect that strategy did not play a large role in determining parents' choices in this first year of school choice, we use the redistricting to test if parents with exogenous changes to the quality of their home school had lower preferences for high-quality schools as would be predicted if parents were behaving strategically. We present this test in Section VII along with other robustness checks. Perhaps because of the uncertainty about the mechanism and the newness of the system, we do not find evidence that strategic behavior played a significant role in this first year of school choice. ${ }^{5}$

\section{Redistricting with the Choice Plan}

Because the public school choice plan replaced a busing plan for racial integration, school assignment zones, which often paired non-contiguous black and white neighborhoods, were dramatically redrawn. Under the choice plan, 43 percent of parcels were assigned to a different elementary grade 'home school' than they were assigned to the year before under the busing system. At the middle school and high school levels this number was 52 and 35 percent respectively. Therefore, in our analysis, the home school

\footnotetext{
${ }^{5}$ In subsequent years of school choice, when capacities at schools were no longer changed to accommodate demand, strategy may have become more important. In the second year of choice, CMS no longer made an effort to accommodate choices by changing school capacities. Many parents received none of their three choices, and expressed frustration because they had made choices without knowing the probability of admittance.
} 
for many students is often not the school they would have been assigned at the time they chose their residence. This dramatic change in school assignment zones implies that residential location was less likely to reflect endogenous sorting based on family preferences for a nearby school.

\section{Heterogeneous Choices}

Interestingly, there was little unanimity in parents' choice of schools. Certainly, much of the variance in parents' top choices is driven by differences in travel times to a given set of schools. But, even among parents with the same elementary home school assignment for 2002-03, parents on average listed on average 10.4 different first-choice elementary schools. ${ }^{6}$ Such a diversity of choices suggests that there is a considerable heterogeneity in preferences, making the mixed-logit demand estimation approach important for understanding demand-side pressure to improve academic achievement in a public school choice setting.

\section{Data Description and Empirical Specification}

\section{Data}

We have secure access to administrative data for all students in CMS for the year before and after the implementation of school choice. Throughout the analysis, we focus on students entering grades 4 through 8 . We focus on this student segment for two reasons. First, younger students do not have baseline standardized test scores. Since we wanted to study the relationship between baseline test scores and parental preferences, and the implications for student sorting in school choice, we focus on students entering fourth grade or higher. Second, we do not consider high school students since high school choice is likely influenced by factors such as graduation rates and athletic programs that are not central to elementary and middle school choices, and thus would be better handled in a separate analysis.

For each student, we have the choice forms submitted to CMS, allowing a student to specify up to 3 choices for their school. In addition to the student choices our data

\footnotetext{
${ }^{6}$ This number accounts for differences in choices listed driven by differences in the prior-year's school.
} 
contain student characteristics for the years before and after school choice, including geocoded residential location, race, gender, lunch-subsidy recipient status, and student test scores for standardized North Carolina End of Grade Exams in math and reading, and school assignment. We use these data to construct key covariates in the demand for schools such as driving distance from each student to each school, an indicator for busing availability, an indicator for the prior year's school, measures of student-level income, student baseline academic achievement, school-level academic achievement, and schoollevel racial composition. The variables used in our model and are described in detail in Section VI and in Table II.

\section{Empirical Model}

Our empirical model uses the parental choices, along with data on each student and school choices, to estimate preferences for school characteristics and how they vary in the population. We estimate a mixed logit discrete choice demand model (McFadden and Train 2000, Train 2003). Mixed logits are multinomial logit choice models with random coefficients on product attributes in the indirect utility function. The mixed logit can approximate any random utility model, given appropriate mixing distributions and explanatory variables (Dagsvik (1994), McFadden and Train (2000)). Standard multinomial logit models impose the independence of irrelevant alternatives (IIA) assumption, which implies that, when choice sets are altered (for example by the introduction of a new school), substitution to any new school does not depend on its similarity to existing schools. In contrast, by introducing individual heterogeneity in preferences over product attributes, the mixed logit model allows for more flexible substitution patterns - generating credible estimates of demand elasticities and simulations, which are key to understanding implications of school choice for competition on quality.

This flexibility, however, comes at some cost. Because of the more complicated functional form, the likelihood function for the mixed logit does not have a closed form, and must be estimated by numerically integrating over the distribution for the random parameters. In addition, changes in the choice set generated by multiple choice data are 
often needed to identify the mean and variance of the preference parameters (Berry, Levinsohn, and Pakes (2004)). The CMS data provide this important source of variation.

Our model is based on a standard random utility framework. Let $U_{i j}$ be the expected utility of individual $i$ from attending school $j$. Individual $i$ chooses the school $j$ that maximizes his or her utility over all possible schools in the choice set. For the first choice, the individual chooses over the set of all available schools (denoted $J_{i}^{1}$ ), so that:

$$
\begin{aligned}
& y_{i j}^{1}=1 \text { iff } U_{i j}>U_{i k} \forall k \in J_{i}^{1} \\
& y_{i j}^{1}=0 \text { otherwise. }
\end{aligned}
$$

The second and third choice (identified by $y_{i j}^{2}$ and $y_{i j}^{3}$ ) is made in a similar manner, except that the choice sets (denoted $J_{i}^{2}$ and $J_{i}^{3}$ ) exclude schools already chosen by individual $i$.

We assume that utility is a linear function of the observed student and school characteristics, $X_{i j}$, such as distance from home, average test scores, and racial composition of the school, plus an unobserved component, $\varepsilon_{i j}$, that reflects unobserved idiosyncratic preference of student $i$ for school $j$.

$$
U_{i j}=X_{i j} \beta_{i}+\varepsilon_{i j}
$$

We assume that the unobservable component $\left(\varepsilon_{i j}\right)$ is distributed i.i.d. extreme value, which yields the usual logit form for the choice probabilities conditional on $\beta_{i}$.

Heterogeneity in individual preferences implies that the coefficients, $\beta_{i}$, in equation (1) will vary across individuals. We allow for this heterogeneity in three ways. First, we allow the parameters of equation (1) to vary randomly across individuals. We assume that $\beta \sim f\left(\beta \mid \mu_{\beta}, \theta\right)$, where $f(\cdot)$ is a multivariate normal mixing distribution, where $\mu$ denotes the mean vector, and $\theta$ represents the variance matrix. Second, we separately estimate parameter distributions for students in each of the four main demographic categories: white and African American by lunch subsidy status. This allows us to compare means and variances of preferences for school characteristics across the different socio-economic groups. Third, we allow the coefficient on a school's standardized score to vary with a student's baseline test score and family income by 
including interactions between these student characteristics and the school mean test score in the vector of characteristics, $\mathrm{X}$.

In the specifications that are reported below, we assume that all random parameters are drawn from a joint normal or log normal distribution. We allow for a covariance between preferences for proximity and school mean test score, since these are key dimensions of product differentiation that might effect competition on academic achievement. Other preference parameters are assumed to be independently distributed.

Given the specification above, the probability that individual $i$ chooses schools $\left(j^{1}, j^{2}, j^{3}\right)$ is given by:

$$
\begin{aligned}
& P_{i}\left(j^{1}, j^{2}, j^{3}\right)=\operatorname{Pr}\left\{\left(U_{i 1^{1}}>U_{i k} \forall k \in J_{i}^{1}\right) \cap\left(U_{i j^{2}}>U_{i k} \forall k \in J_{i}^{2}\right) \cap\left(U_{i j^{3}}>U_{i k} \forall k \in J_{i}^{3}\right)\right\} \\
& \int \prod_{c=1}^{3} \frac{e^{X_{i j^{c}} \beta}}{\sum_{k \in J_{i}^{c}} e^{X_{i k} \beta}} f(\beta \mid \mu, \theta) d \beta
\end{aligned}
$$

The term inside the integrand represents the probability of observing the three ranked choices conditional on the preference coefficients $(\beta)$ : this is the product of three logit probabilities evaluated at $\beta_{i}$, corresponding to the probability of making each choice from among the remaining options. ${ }^{8}$ This conditional probability is integrated over the distribution of $\beta$ to yield the unconditional probability of observing the ranked choices.

These probabilities form the log-likelihood function:

$$
L L(X, \mu, \theta)=\sum_{i=1}^{N} \sum_{j=1}^{J_{1}} \sum_{k=1}^{J_{2}} \sum_{l=1}^{J_{3}} y_{i j}^{1} y_{i k}^{2} y_{i l}^{3} \ln \left(P_{i}(j, k, l)\right)
$$

Since equations (2) and (3) do not have a closed form solution, simulation methods were used to generate draws of $\beta$ from $f(\cdot)$ to numerically integrate over the distribution of preferences. Estimation was by the method of maximum simulated likelihood, using 100

\footnotetext{
${ }^{7}$ Allowing for general covariance structure across all parameters led to instability in the estimated covariance terms in some specifications, but did not significantly affect the remaining parameters or the substantive results that we report.

${ }^{8}$ For students submitting fewer than three choices, the likelihood is modified in an obvious way to reflect only the probability of the submitted choices.
} 
draws of $\beta$ from $f(\cdot)$ for each individual in the data set. The results were not sensitive to increasing the number of draws used.

\section{Descriptive Statistics}

The CMS choice form allowed parents to list up to three school choices. The availability of more than one choice for students in CMS helps in the identification of the preference parameters. Intuitively, when only a single $\left(1^{\text {st }}\right)$ choice is observed for every individual, it is difficult to be sure whether an unexpected choice was the result of an unusual error term $\left(\varepsilon_{i j}\right)$ or unusual preferences by the individual ( $\left.\beta_{i}\right)$ for some aspect of the choice. However, when an individual makes multiple choices that share a common attribute (e.g. high test scores) we can infer that the individual has a strong preference for that attribute, because independence of the additive error terms across choices would make observing such an event very unlikely in the absence of a strong preference. When we take away the first choice and ask parents which school they would like for their child instead, the researcher can observe in which direction parents substitute, and infer something about their preferences for school characteristics.

Table I provides summary statistics on all of the students who submitted choice forms for the entire sample, broken down by race and lunch subsidy status. Overall, 95\% of students submitted choice response forms. Whites and Blacks each comprise just over $43 \%$ of the school population. Approximately 10 percent of white students receive federal lunch subsidies, while just over 60 percent of African Americans do. Since parents were guaranteed a slot in their default school, many parents listed only one or two schools on their choice forms. In particular, students who were white and ineligible for lunch subsidies were more likely to fill out only a first choice. Table I shows that the average scores for their home schools were one quarter to one half of a standard deviation higher than those of other groups. Between $46 \%$ and $63 \%$ of parents in the remaining subgroups submitted all three choices. Note that 20-46\% parents who listed their home school first, listed subsequent choices. For instance, $42 \%$ of non-white students who were not receiving federal lunch subsidies chose their home school first, while only $28 \%$ listed 
only a first choice. Whatever their reasons for doing so, the availability of multiple choices from those who listed their home school first will further aid in the identification of the preference parameters.

Table I also provides the mean and standard deviation of baseline test scores of students in CMS in Spring 2002 by race and lunch-subsidy status. Student-level test scores are reported as the standardized score - standardized by the mean and standard deviation in the district for students in each grade. Hence, a value of zero implies students who scored the average relative to all other students in their grade in the district. While there are large differences in average test scores across the groups of students, there is substantial variation in student ability within each category as measured by performance on standardized tests. Similarly, the within-school and within-neighborhood variation is greater than across-school or across-neighborhood variation in student achievement. Such variation in student level-baseline achievement within and across schools, neighborhoods, and socio-economic groups will help identify the degree to which preferences for school quality vary with own academic ability.

Finally, because schools had historically been placed for the busing for integration program, high-scoring schools (some of them magnet programs) are dispersed throughout the county, located in both urban and suburban areas, and in both minority and nonminority communities. Table I reports the average travel distance (in miles) to the nearest school in the top quartile of average test scores. The average student in all four categories lives within 2-3 miles of a top-quartile school. Figure 1a presents a map of school locations and their test scores against the demographic characteristics of census block groups in Mecklenburg County (measuring approximately 22 miles across and 30 miles north to south), while Figure 1b shows an up-close example for a particular set of neighborhoods measuring roughly 4.5 miles across. Darker shading identifies block groups where more of the population is African American and identifies schools with higher average test scores. Note that many neighborhoods are racially integrated - with at least $20 \%$ of either race present. Neighborhoods that vary greatly in their racial composition are roughly the same distance to the same set of schools, and students in most neighborhoods can choose from schools with a wide range of average test scores. 
Such variation will help us identify preferences for school proximity and school quality across the socio-economic groups of interest.

\section{Results}

The mixed logit model was estimated separately by race (white vs. non-white) and by receipt of federal lunch subsidies. Therefore, all estimates for both the means and variance-covariance matrices of the preference parameters were allowed vary across race and lunch-subsidy status. Within race and lunch-subsidy status, we included as explanatory variables measures of school and student characteristics that are central to understanding competition on quality in the context of the school choice debate. To capture the importance of proximity and travel costs, the specification included driving distance (in miles) from the student's residence to the school (measured in miles), an indicator if busing was provided for the student to the school (the school was in the student's zone), and an indicator if the school is the student's neighborhood school. An indicator if the student attended the school in the prior year was included to capture the importance of continuity for students who were continuing in elementary or middle school. To capture the academic quality of the school, we calculate the average 2002 standardized test score for students attending the school in 2003 (Cullen, Jacob, Levitt (2006)). We interacted the school's average test score with the student's standardized baseline test score (standardized by grade level across the district) and the median household income in the student's neighborhood for the student's race (measured in \$1000's, using their census block group in 2000, and de-meaned with the countywide median of $\$ 51,000)$. These interactions allowed the effect of school test scores on school choice to vary with a student's income and academic ability. Finally, to capture the racial composition of a school, we included the percent black in the school in Spring 2003 and its square. When the quadratic term has a negative coefficient, this specification yields an implied bliss point (where the quadratic peaks) for preferences over racial mix of a school.

The final estimation sample includes 36,816 students entering grades 4-8. The means and standard deviations of these variables across the over 2 million school choice 
and student choice interactions available to our sample of students and schools are reported in Table III. The mixed logit parameter estimates are reported in Table IV. All of the point estimates were precisely estimated and statistically different from zero at less than the 1 percent level. To preserve space, the standard errors of the estimates of the preference distribution means and standard deviations are reported in Appendix Table I.

\section{Proximity: Travel Distance, Neighborhood Schools, and Bussing Zones}

Given strong priors that the coefficient on distance would be non-positive, we imposed a lognormal distribution on the preference coefficient for distance: $\beta_{\text {dist }}=-\exp (\alpha)$, where $\alpha$ was assumed to be normally distributed. In the table we report the mean and standard deviation for the actual coefficient ( $\beta_{\text {dist }}$ ) rather than for the underlying normal $(\alpha)$. The negative weight placed on distance is fairly uniform across the four demographic groups. However the effect of distance is slightly larger in absolute value for white students compared to black students, and slightly more variable for students receiving lunch subsidies. For an average student, each additional mile of distance reduces the odds of choosing a school by roughly 35\% among whites and $27 \%$ among nonwhites. The standard deviation in this effect across students is $15 \%-30 \%$ of the mean, implying that for some students distance is a major barrier to choice while other students place very little weight on distance.

Preferences for home school are strong on average across all demographic groups; however there is also a large variance in the strength of the home-school preference within each group. The pattern for home school preference is similar to that found for distance: The mean preference for a home school is somewhat larger for whites, and somewhat more variable for students eligible for lunch subsidies. The mean effect is roughly equivalent to 5-7 miles in travel distance in each sub-sample of students.

Because the home school is often the closest school to the student, this variable may pick up a non-linearity in preferences for proximity (parents have an added preference for the closest school to them). However, it may also represent a preference for a "neighborhood school," where there may be social or informational benefits to attending the same school as other kids in the immediate neighborhood. We investigated the degree to which the estimated preference for a home school reflects a non-linear 
preference for proximity versus a value of neighborhood school by re-estimating the model on a sample of students living along newly-created home-school boundary borders that bisected old school assignment zones. To the extent that these students had attended the same schools in the prior year, and faced a similar distance to all schools, we hoped to better isolate the importance of the home school designation. The preference for a home school was lower for students living on the boundary of a home school zone, but still positive and significant. Hence there appears to be a preference for the neighborhood school in addition to a non-linear component of preference for proximity.

Another possibility is that the home school indicator is picking up a default effect, rather than a preference for neighborhood school. If parents do not want to invest the time to fully consider all the schools in the choice set, they may simply list their guaranteed school as their first choice. ${ }^{9}$ This would imply a stronger preference for a home school on the first of the three choices. We estimated the mixed logit model with a separate coefficient on the home school indicator for just the first choice. Default behavior as described above should imply a positive coefficient on the home school indicator interacted with first choice. We found that the coefficient was smaller, and within one half of one standard deviation of the mean overall preference distribution for a home school. Hence, we interpret the coefficient on the home school indicator as picking up a preference for the 'neighborhood school' instead of picking up a default behavior.

Finally, the coefficient on a school being in a student's choice zone was intended to capture lower travel costs to these schools, since transportation by the district was only provided to schools within a student's own choice zone. All four demographic groups have a strong mean preference for schools in their choice zone, with the effect being largest among students who are eligible for lunch subsidies (as would be expected if these students had limited access to alternative transportation). The standard deviation of the coefficient on choice zone is of roughly the same size as the mean in each demographic group, suggesting considerable variation across students in these preferences.

Overall, the estimates for travel distance, neighborhood schools, and choice zones support the same general conclusion. While there are some differences across

\footnotetext{
${ }^{9}$ Note this is different than defaulting by not turning in a choice form. Recall that $95 \%$ of parents submitted the choice forms. Of these, defaulting behavior might be an over-propensity to list Home School first, and nothing else.
} 
demographic groups, it is clear that proximity is an important determinant of school choice for the average student. At the same time, there appears to be great heterogeneity across students in the weight that they place on proximity in choosing a school.

\section{School Test Scores}

Given our prior that preferences for school scores would vary with student baseline academic ability as well as student income level even within race and lunchsubsidy status, we included school test scores and their interaction with the student's baseline test score and neighborhood income level. For students who are eligible for lunch subsidies, we did not include the interaction with neighborhood income because all of these students are presumably very low income. ${ }^{10}$ Both neighborhood income and the student's baseline score are “de-meaned”, so that the coefficient on the main effect of school score measures the value of school test score for a student with average income and baseline test score (both equal to zero). The coefficient on the main effect (the school test score) was treated as a random parameter, allowing for additional variation in preferences for school scores (beyond that explained by income and baseline test score).

These estimates yield a number of interesting findings. For an average student, the mean preference for school scores is larger for non-white students within lunch-subsidy status, but students not eligible for lunch subsidies value school scores much more than their lunch-eligible peers. The difference between those who were receiving lunch subsidies and those who were not is consistent with the coefficient on the interaction with neighborhood income. Higher neighborhood income was strongly associated with higher mean preference for school scores, with a similar effect for both whites and non-whites. The difference in the mean preference between students receiving lunch subsidies and students not receiving lunch subsidies (about 1.0 within each race group) is roughly what would be predicted by a $\$ 70$ thousand dollar income difference (based on the coefficient from the income interaction), which is roughly the right order of magnitude for the income difference between these groups.

\footnotetext{
${ }^{10}$ In initial specifications using a conditional logit, income interactions with the preference for school scores were insignificant for the lunch-recipient segments.
} 
The mean preference for school scores is also increasing in the student's baseline test score. The coefficient on the interaction between the standardized value of one's own test score and the school mean test score is positive. The coefficient varies somewhat across groups (with white free-lunch students having the smallest coefficient), but there is no obvious pattern by race or free-lunch status. The effect of a student's baseline score on the preference for school test scores is similar in magnitude to the effect of income: A one standard deviation increase in the baseline test score is associated with a 0.29-0.46 increase in the mean preference for school test scores, while a one standard deviation increase in neighborhood income (about \$27,000) is associated with a 0.37-0.39 increase in the mean preference for school test scores.

While the mean preferences for school test scores appear to be somewhat stronger for non-whites the heterogeneity in preferences within racial groups is considerable. Differences in baseline test scores and income each generate a standard deviation in preferences of roughly 0.3-0.4 based on the calculations from the previous paragraph. In addition, the variance on the coefficient for the main effect of school test scores is also estimated to vary with a standard deviation ranging from 0.3 to 0.7 . Taken together, the total variation in preferences for school test scores across individuals is substantial.

\section{Covariance in Preference Trade-offs Between Proximity and School Scores}

For a student with average preferences, the preference for proximity is very large relative to the preference for school test scores. For example, an average student with average preferences who was not receiving lunch subsidies would choose their home school over a school three miles further away in which average test scores were 1-2 standard deviations higher, ceteris paribus. For the average student receiving lunch subsidies, the difference in school test scores would have to be even larger to induce them to switch. However, there is a large variance in preferences for school test scores, and the idiosyncratic preference for school test scores is negatively correlated with the preference for the home school across all of the four demographic groups, with particularly strong correlations amongst African-Americans who do not receive lunch subsidies. This implies that, while many students are very inelastic with respect to school test scores, there is a significant density of students who highly value school scores and have low 
preferences for their neighborhood school. These students are willing to consider schools outside of their neighborhood, and they place a high weight on average test scores when picking a school.

Taken together, these estimates for the distribution of preferences for distance, home school, and school mean test score imply that there tend to be two types of parents: i) those who highly value proximity through their neighborhood school and are not likely to choose another school without substantial improvements to average school scores, and ii) those who place little value on proximity through their neighborhood school and place a large value on school scores. The first type of parent is highly inelastic to school quality as approximated by average test scores. Student of this type of parent will be served by their local school, and will stay with that local school even in the face of potentially large losses to relative school quality. The second type of parent is very elastic with respect to school quality - willing to travel over a relatively broad geography for a modest gain in school scores. ${ }^{11}$ These underlying characteristics of the preference distribution have important implications for demand-side pressure for competition on school quality which we will discuss further in Section VIII.

\section{Racial Composition}

While student preferences for school racial composition are not the focus of this paper, we must account for racial composition since it is correlated with average test scores of the school. To capture the racial composition of a school, we included the percent black in the school and its square. When the quadratic term has a negative coefficient (which was always the case), this specification can be interpreted in terms of an implied bliss point (where the quadratic peaks) for preferences over racial mix of a school, and a quadratic loss function for differences from this bliss point. In Table IV, we report the estimates for the linear and quadratic terms, along with the implied bliss point. We allowed for a random coefficient on the linear term but not the squared term, which is equivalent to allowing for unobserved heterogeneity in the bliss point but not the

\footnotetext{
${ }^{11}$ Interestingly, casual interviews of parents in CMS revealed this same pattern. Parents either seemed to choose their neighborhood school with out much knowledge of other schools in the district, or parents seemed to know a lot about academic outcomes for many schools in the district, and based on that, tended to select a preferred school that was typically not their neighborhood school.
} 
quadratic loss around that bliss point. Other specifications, such as dummies for ranges of percent black or a spline in percent black, yielded similar results.

Not surprisingly, there were large differences between the races in their valuation of a school's racial composition (and little difference by lunch-subsidy status). The mean bliss point for whites was around 30\% black, while the mean bliss point for non-whites was around $80 \%$ black. Thus, the average preferred school for each racial group was one in which $70 \%-80 \%$ of the school was their own race. The quadratic term was negative for all demographic groups, but was larger for whites than non-whites, and larger for freelunch ineligible than for eligible. These results are quite consistent with an earlier literature highlighting racial differences in stated preferences regarding the racial composition of neighborhoods. In that literature (surveyed in Armor (1995)), whites preferred neighborhoods that were 10 to 30 percent black and blacks preferred neighborhoods that were roughly 50 percent black.

The focus of this current paper is on preferences for school quality rather than preferences for racial composition. Given the history of bussing for integration in CMS, and the higher-than average private school attendance of whites in the district, it is not clear that these racial preference estimates generalize outside of settings similar to this one. ${ }^{12}$ However, because school test score is negatively correlated with the percent black in the school (with a correlation coefficient of approximately -.67), failing to deal with explicit racial preferences would lead us to understate black student valuation of school scores since they prefer schools with above-average black enrollment. Failing to account for school racial composition would have led to the false conclusion that whites care much more about school scores than black students.

\section{Robustness Checks}

There are a number of reasons that the estimates in Table IV may not accurately represent student preferences. In this section we present a series of robustness checks that address three particularly important concerns that could lead our estimates to understate

\footnotetext{
${ }^{12}$ Approximately $12-15 \%$ of students attend private schools in CMS compared with 8-9\% in the state of North Carolina, and 9-10\% in the U.S as a whole.
} 
the strength of preferences for academic quality at a school. These specification checks do not find evidence that the preference estimates in Table IV are biased by any of these three important concerns.

\section{Alternative Measures of Academic Quality}

In Table IV, we used average base-year (2002) test scores among students attending the school in 2003 as a measure of academic performance that influences parents' choices. However, if this is a crude or incorrect proxy for the information available to parents, then our estimates may understate the extent to which parents care about academic performance in choosing a school. Table V presents mixed logit results for our original measure plus three alternative measures of school academic performance. To preserve space, we only report the coefficients on the measure of school academic performance (and its interactions with income and student baseline score), along with the log likelihood for each model as an indicator of overall fit. The first panel replicates our baseline specification. This specification assumes that parents correctly forecasted which students would choose each school, and used these students' scores from the prior year as an indicator of how good the school would be in terms of academics. The second panel uses the average score in 2003 of the students in the school in 2003. This measure implies that parents correctly foresaw student sorting and outcomes and made their choices based on that. The third panel uses the 2002 average scores for students in each school in 2002. This measure implies that parents used historical student assignment and outcomes as the best indicator of future school performance. The final panel uses a "value-added" measure of each school's impact on academic achievement in the prior year. We estimated each school's “value-added” by regressing a student's test score performance in 2003 on math and reading performance in the prior year, demographic characteristics, grade fixed effects, and fixed effects for each school. The fixed effect estimated for each school represents our estimate of a school's average impact on student performance.

The results in Table $\mathrm{V}$ show that the preference estimates across the three measures of average test scores are quite similar. The specification in panel 1, using our base specification, has the highest likelihood value, and in this sense fits the choice data best. The value-added measure in Panel 4 does not fit the observed choice data well at all. 
This may not be surprising since this statistic is not available to parents and is not easy to calculate given the available average score statistics. Cullen, Jacob, and Levitt (2006) report that high-demand schools in Chicago's high school choice program tend to be schools with high average test scores, not high value-added. Note that our specifications using test score levels do allow parents to make a crude race-adjusted 'value-added' calculation when choosing a school (since these specifications separately control for racial makeup of the school).

Overall, the results from Table V suggest that our preference estimates are not particularly sensitive to the use of reasonable alternative measures of school academic performance. Because our baseline specification provides the best fit of the data, we will rely on this specification for the final simulations.

\section{Strategy}

As noted above, parents may have had an incentive to misrepresent their true preferences. If they understood the allocation mechanism, a parent with an undesirable home school might want to hedge against being assigned to the home school. They would do so by picking less desirable schools than they actually prefer - trading off desirability for increased chance of being admitted. This strategy could make it appear that lowincome families (with lower-performing home schools) under-value academics even though they do not. They pick lower performing schools in order to increase their chance of admission, not because they place a lower weight on academics. However, it is not at all clear that parents had the information or experience in the first year of choice to understand how to exploit the incentives of the allocation mechanism. Parents did not know their lottery numbers or the assignment mechanism. In addition, parents were instructed by the district to list the schools they wanted on their choice form. ${ }^{13}$

We test for the presence of strategic behavior in the first year of choice by exploiting the redrawing of school boundaries. Many of those who lived in the same contiguous school assignment zone in 2001-02, were given different school assignments

\footnotetext{
${ }^{13}$ This stands in contrast with other long-standing and limited choice programs, such as the Boston Public School choice program which told parents to consider carefully what schools they chose to list (Abdulkadiroglu et. al (2006)). Abdulkadiroglu et. al (2006) also show that many parents appear to behave non-strategically in Boston Public Schools limited and long-standing school choice program, and that these parents would benefit most from strategizing on their first choice by picking a less popular school first.
} 
in 2002-03. Hence, among those with the same school assignments who lived in the same neighborhood in 2001-02, some students experienced positive or negative shocks to the quality of their guaranteed school. Table VI shows the average difference for students who had positive versus negative shocks to their home school quality given that they lived in a 2001-2002 contiguous assignment zone that was split into new assignment zones. The table shows that the difference in scores was large and significant for many of the students affected by redistricting. If strategy was a major component of parental choices, we would expect to see very different choices for those with negative versus positive shocks to the quality of their home school, given a contiguous 2001-2002 school assignment zone. In particular, we should see significantly lower weight placed on average test scores for students who had a negative shock to the average quality of their home school.

Table VII presents a simple conditional logit specification using the first choices for the sub-sample of students who lived in 2001-2002 assignment zones that were split by redistricting. The results are estimated on the sample of those students who had a positive shock and those that had a negative shock to their home school quality. Standard errors are clustered at the prior-year's school assignment zone. The results show that there is no significant difference in the school-score preference estimates for redistricting losers versus winners. ${ }^{14}$ In addition, the point estimates do not follow the expected pattern if strategy was a key component in choosing schools. Preferences for test scores are higher (in bold) as often as they are lower for the redistricting losers.

Overall, we do not see evidence that parents with poorer home school assignments hedged their bets. It is possible that such strategic behavior may develop over time as parents became more familiar with the system. ${ }^{15}$ Our evidence, suggests that

\footnotetext{
${ }^{14}$ We also tested for differences in preferences using a reduced form regression of the average test score of the chosen school on the average test score at the home school, controlling for 2001-2002 school assignment fixed effects and student demographic information. This compares the average scores of $1^{\text {st }}$ choice schools within 2001-2002 assignment zones across students with positive and negative shocks to home school quality. We find no significant difference in the average scores of schools chosen across redistricting winners and losers.

${ }^{15}$ Evidence from laboratory experiments using simple extensive-form games between small numbers of players indicates that it takes time for players to learn how to play the game. In games with incomplete information on other's pay-offs, learning and convergence to the perfect equilibrium is slower and sometimes does not occur (Roth and Erev (1995)).
} 
there is little evidence of hedging behavior in the first year of choice when parents most likely did not understand the allocation mechanism.

\section{Residential Sorting}

The exogenous redistricting of nearly half of the students in the district is also useful for testing the extent to which residential sorting affects our preference estimates. Residential sorting may lead us to overstate preferences for proximity if parents had already sorted to live next to the schools they prefer. What we interpret as a strong preference for proximity influencing school choice may actually be the opposite - strong preference for a school influencing proximity. Both redistricting and the multiple choices in our data will help identify preferences for proximity from preferences for other school characteristics.

To test for the potential effects of residential sorting on our estimates, we reestimate our model for the sub-sample of students who were redistricted (whose school assignments under the bussing plan in 2001-2002 were different from their home school in 2002-2003). ${ }^{16}$ Table VIII provides summary statistics comparing the redistricted sample to the sample of students who were not redistricted. Because of the nature of the prior system of bussing, students who were redistricted were much more likely to be nonwhite and eligible for lunch subsidies. (The busing plan often assigned students living in neighborhoods with large concentrations of minority students to attend school in neighborhoods with lower concentrations.) But within the four demographic groups, the redistricted students looked similar to those who were not redistricted in terms of baseline test scores and median income. More interestingly, the redistricted students were much less likely to choose their home school or their last year's school, and much more likely to list three choices. These facts are not necessarily evidence that redistricted students have less preference for their home school: Students who were not redistricted were more likely to have their home school be their last year's school, making it very likely that they would choose that school. In contrast, redistricted children faced a less clear choice since their last year's school was no longer their home school.

\footnotetext{
${ }^{16}$ These students include both students who’s 2001-2002 school assignment zone was split into two new home school zones as well as those who's entire 2001-2002 school assignment zone was reassigned to a new home school.
} 
Table IX reports results from the mixed logit model estimated on the sample of students who were redistricted. The most striking feature of these estimates is their similarity to estimates from the full sample. Estimates of the mean and standard deviation of all the preference parameters are qualitatively and quantitatively similar. The mean of the parameter for home school is actually higher for all demographic groups in the redistricted sample, while the means for the distance and choice zone parameters are about equally likely to increase as decrease in the redistricted sample.

Overall, these estimates suggest that endogenous residential location is not a major source of bias in this data. In addition, the similarity of the results is not too surprising if we believe our model is using the information in multiple choices to identify preferences. Recall from Table I that a substantial fraction of parents who listed their home school as their first choice also listed subsequent choices. For these parents, multiple choices simulate redistricting whether or not they were actually redistricted.

\section{Other Robustness Checks}

A range of alternative specifications yielded similar quantitative and qualitative results. We have pooled elementary and middle school students for simplicity, but estimating the model separately for elementary and middle schools yielded similar parameter estimates. As already mentioned, we experimented with alternative specifications for the racial composition of the school, including dummy variables and splines in percent black. The spline estimates were very consistent with the more parsimonious quadratic specification.

We also specified distance to each school in terms of driving time (based on expected speed on each class of road) rather than driving distance, yielding nearly identical results. In addition, estimations using splines in distance indicated that the linear functional form used in our model was appropriate. We experimented with a range of alternative proxies for academic quality of a school. Using closely related measures such as the average percentile score resulted in nearly identical estimates. Allowing for nonlinearities in the effect of school scores, through a quadratic or spline term, did not change the qualitative implications of the parameter estimates. However these models fit the data poorly in the tails of the distribution, and for this mechanical reason they 
generated implausible results when used in simulations. In addition, estimates using splines in school test scores indicated that the linear model fit the data well for most segments of the population. Including separate terms for the school average test scores of whites and non-whites separately resulted in all students, both white and non-white, placing similar weights on the two scores, with both racial groups placing a larger weight on white test score performance. Again, the implications of the results were unchanged across these specifications. Finally, including a separate dummy variable for schools that were academic magnets (e.g. International Baccalaureate, Math and Science magnets) reduced the mean coefficient on school test scores about in half. This result highlights that average test scores are a proxy for the academic focus of a school, and not necessarily the sole causal factor driving demand.

Finally, when we estimated a general mixed-logit model with full covariance terms for the parameters, we found that some covariance terms became unstable in some specifications. For example, when we included a covariance between racial preferences and preferences for other characteristics could often be unstable, yielding corner solutions in some circumstances. However, the means and standard deviations of the preference parameters were largely unchanged, and the implications of the estimates in the demand simulations were very similar. This suggests that some of the covariance terms are poorly identified, but that these terms are not of first order importance to simulations of demand.

\section{Simulations}

In the discussion of the results above, we focused primarily on the mean weight attached to various school attributes. However, the aggregate response to any policy change will depend not only on the mean parameter estimate, but also on the variance or distribution of that parameter in the population. As noted in the introduction, a key issue in the policy debate over school choice is the elasticity of demand with respect to school test scores. In order to shed some light on this question, we took each school individually, added .33 average student-level standard deviations to its mean school score holding all else equal, and simulated the change in the number of students listing that school as a 
first choice. ${ }^{17}$ The simulated change in demand was a local approximation (based on the derivative of demand), so these simulations should be interpreted as the impact of a small change in school test scores.

Figures $2 \mathrm{a}$ and $2 \mathrm{~b}$ plot the change in number of students listing a school as a first choice by the school's original average score (each point in the figure is the result of a simulation for a different school: 2a plots elementary schools, 2b middle schools). Because of the difference in size, we plot the results separately for elementary and middle schools. The demand response is quite different for schools that were originally high and low-scoring. The upward sloping relationship implies that the demand response is greatest among schools that were already high scoring. This result reflects the parameter estimates in the mixed logit model. Parents with high preferences for school scores, and thus low preferences for their neighborhood school, are sensitive to changes in school scores and willing to consider schools over a relatively broad geography. These parents are both likely to only consider high scoring schools for their children and willing to change schools in response to an increase in score at another high scoring school, even one that is located further away. These results imply that the incentives to focus on student performance are larger for higher performing schools, since schools above a critical performance level compete intensely on academic quality for the quality-elastic segment of the population.

Figures 3 and 4 plot differences in mean characteristics between the marginal students (those who are drawn in by the .33 average student-level standard deviation score increase) and students who previously enrolled in each school. The incentive for any school to improve its performance would be dampened if, in doing so, they were swamped by lower-performing and or lower-income students, who would bring down mean performance and potentially be more costly to educate. Figure 3 compares marginal and average students in the percentage receiving lunch subsidies; Figure 4 compares mean test scores for the marginal and average student. The points below the $45^{\circ}$ degree line in the Figure 3 indicate schools where a lower proportion of the marginal students received lunch subsidies than the average student. It is evident in graph that the marginal

\footnotetext{
${ }^{17}$ This is approximately equivalent to a 10 point increase in the average percentile score for students attending that school.
} 
students had lower rates of lunch subsidy receipt than the students already enrolled. In other words, the marginal students were more affluent than the students already enrolled in most schools. Figure 4 reports differences in mean test score between the marginal student and the average student previously enrolled in the school. The fact that most points were above the $45^{\circ}$ line implies that the marginal students, on average, were higher performing than the students already enrolled.

The key features of the simulations reported in Figures 2-4 appear to be driven primarily by the estimated heterogeneity in preferences, rather than other details of the specification. In all the alternative specifications we have estimated that allowed for heterogeneity in preferences, we found that an increase in school test scores had a much larger effect on demand in high scoring schools, and attracted higher-performing and higher-income students to the school (particularly at low scoring schools). Eliminating unobserved heterogeneity in preferences (estimating a conditional logit) reduces the simulated difference in demand response to higher performing schools by roughly $15 \%$. Eliminating preference heterogeneity through observable characteristics (income, race, lunch-subsidy status and baseline test scores) further decreases the difference in demand response across high and low performing schools, leading to a low demand response across all schools. Thus, heterogeneity in preferences appears to be a key element in understanding the properties of parental demand for schools and their implications for student sorting and demand-side pressures for school quality in a public school choice program.

The implications of these simulations are very interesting for school choice policy design. On one hand, they suggest that the absolute enrollment responses to improvements in performance are small at schools that start out low-performing. The enrollment responses are much larger at schools that start out higher performing suggesting that demand-side forces may lean toward greater vertical separation on test scores. In the long run, the new equilibrium will depend on the incentives provided to school managers and steps districts can take to influence demand for school quality particularly among low-income households. If a greater percentage of resources are directed towards high demand and high performance schools, top tier schools will have strong incentives to improve student performance, while lower-tier schools may not. 
However, district policies that commit to close schools or replace principals in schools with shrinking enrollments coupled with financial incentives for performance may minimize the degree of vertical separation. For example, North Carolina has provided bonuses to teachers in schools with test score improvements and, with the No Child Left Behind Act of 2001, the federal government has required states to penalize schools with poor test performance. Moreover, the district has replaced principles at schools with low

enrollments and moved to close and reorganize schools at the lowest end of performance (and enrollment). In addition, marketing and outreach efforts that increase the choice responsiveness of low-income and minority families to academic achievement may increase the pressure on all schools to provide quality education under public school choice, abating the tendency towards increased stratification of schools.

\section{Conclusion}

This paper used a school choice policy experiment and detailed student-level data to examine parental preferences for key school characteristics. We employed a mixed logit demand estimation approach which allowed parents' preferences to vary with observable characteristics as well as idiosyncratically. We show that preferences for measures of academic achievement are increasing in income and baseline academic ability. In addition, parents who have a low idiosyncratic preference for their neighborhood school have a higher idiosyncratic preference for school test scores.

The distribution of preferences has important implications for school choice. Simulations based on our preference estimates indicate disparate demand-side pressure for schools to improve academic performance. High performing schools serve families who value academics, and receive a large demand response to increases in average test scores. Consumers of low-performing schools are local families who are less responsive to changes in school academic performance. These 'local monopolist' schools face little demand-side pressure to improve and serve, on average, families with lower income and lower baseline academic achievement.

By using unique data and a large school-choice policy experiment, we were able to take a demand-estimation approach to understanding competition in a school choice 
program. This approach has several benefits. First, it contrasts with prior approaches which use HHI's to measure competition in the market for schools and predict the effects on achievement of increased parental choice. In a differentiated products market, preferences play a key role in determining demand and competition. By estimating preferences we can examine models of consumer choice implicitly excluded by models relying on HHI's and similar measures of market concentration. Secondly, understanding preferences can elucidate policy measures that may increase competition in a school choice program. For example, school districts may design information systems, school choice guides, or counseling resources to increase the value that low-income families place on academic performance. Districts may also use demand-response as a basis for school closure and reorganization decisions, adding powerful supply-side pressure to school administrators. Preference estimates can also be used to examine placement of new schools for maximal impact on competitive pressure. Furthermore, preferences may assist in theoretical simulations of expanded choice plans and alternative assignment mechanisms. Finally, the gains to students from exercising choice are likely to depend on parents' objectives when choosing schools, and heterogeneity in preferences may explain disparate impacts of school choice on student academic achievement (Hastings, Kane, and Staiger, 2006). Thus, preferences drive parental (consumer) choice, and their distribution in the population affects competition, sorting, and gains to academic achievement in school choice programs. 


\section{References:}

Abdulkadiroglu, Atila and Tayfun Sonmez "School Choice: A Mechanism Design Approach”, American Economic Review, 93(3):729-747, June 2003.

Abdulkadiroglu, Atila, Parag A. Pathak, Alvin E. Roth, and Tayfun Sonmez "Changing the Boston School Choice Mechanism: Strategy-proofness as Equal Access,” working paper, Harvard University, May 2006.

Anderson, Simon P., André de Palma, and Jacques-François Thisse, Discrete Choice Theory of Product Differentiation, The MIT Press: Cambridge, Massachusetts, 1992.

Armor, David J. Forced Justice: School Desegregation and the Law (Oxford: Oxford University Press, 1995).

Armor, David J. and Peiser, B.M. "Interdistrict Choice in Massachusetts" in Paul Peterson and Bryan Hassel (eds.) Learning from School Choice. (Washington, DC: Brookings Institution Press, 1998).

Bayer, Patrick, Fernando Ferreira and Robert McMillan, “Tiebout Sorting, Social Multipliers and the Demand for School Quality,” NBER Working Paper No. 10871 (2004).

Belfield, Clive and Henry Levin, "The Effects of Competition on Educational Outcomes: A Review of US Evidence,” Working Paper (2002), National Center for the Study of Privatization in Education.

Berry, Steven, J. Levinsohn and A. Pakes (2004), “Differentiated Products Demand Systems from a Combination of Micro and Macro Data: The New Vehicle Market,” Journal of Political Economy, 112(1), 68-104.

Berry, Steven, J. Levinsohn and A. Pakes (1995), “Automobile Prices in Market Equilibrium,” Econometrica, 60(4), 889-917.

Borland, M.V. and R.M. Howson, “Students' Academic Achievement and the Degree of Market Concentration in Education," Economics of Education Review, Vol(11):31-39, 1992.

Cullen, Julie Berry, Brian A. Jacob and Steven Levitt (2006), “The Effect of School Choice on Student Outcomes: Evidence from Randomized Lotteries” forthcoming, Econometrica.

Dagsvik, John, "Discrete and Continuous Choice, Max-Stable Processes, and Independence from Irrelevant Attributes,” Econometrica, 62(5):1179-1205, September 1994. 
Dahl, Gordon, "Mobility and the Return to Education: Testing a Roy Model with Multiple Markets,” Econometrica, 70(6):2367-2420, November 2002.

Dubin, J. and D. McFadden, “An Econometric Analysis of Residential Electric Appliance Holdings and Consumption,” Econometrica, 52:345-362, 1984.

Epple, Dennis and Richard Romano (1998), "Competition Between Private and Public Schools, Vouchers, and Peer-Group Effects.” American Economic Review, Vol(88) no.1: pp.33-62.

Epple, Dennis and Richard Romano (2002), "Educational Vouchers and Cream Skimming,” NBER Working Paper No. W9354.

Farrell, Joseph and Carl Shapiro, "Horizontal Mergers: An Equilibrium Analysis," American Economic Review, Vol.(80) no.1.: pp.107-126, 1990.

Glazerman, Steven, "Determinants and Consequences of Parental School Choice” Unpublished working paper, University of Chicago, Harris School of Public Policy, (December 21, 1997).

Glazerman, Steven and Robert H. Meyer, "Public School Choice in Minneapolis," in T.A. Downes and W.A. Testa, eds., Midwest Approaches to School Reform. Proceedings of a conference held at the Federal Reserve Bank of Chicago, 1994, pp.110-126.

Hanushek, Eric and Steven Rivkin, "Does Public School Competition Affect Teacher Quality?” in Caroline Minter Hoxby (ed.), The Economics of School Choice (Chicago: University of Chicago Press, 2003), pp. 23-47.

Hastings, Justine S. Thomas Kane and Douglas Staiger (2006), "Preferences and Heterogeneous Treatment Effects in a Public School Choice Lottery,” NBER Working Paper No. 12145.

Hausman, J., and D. Wise (1978): "A Conditional Probit Model for Qualitative Choice: Discrete Decisions Recognizing Interdependence and Heterogeneous Preferences," Econometrica, 46, 403-426.

Hoxby, Caroline M. "Does Competition among Public Schools Benefit Students and Taxpayers?” American Economic Review (2000) Vol. 90, No. 5, pp. 1209-1238.

Hoxby, Caroline M. “Do Private Schools Competition for Public Schools?” NBER Working Paper No. 4978, 1994. 
Kagel, John H. and Alvin Roth, "the Dynamics of Reogranization in Matching Markets: A Laboratory Experiment Motivated by a Natural Experiment," Quarterly Journal of Economics, February (2000), pp. 201-235.

Karp, Jeffrey A. and David Brockington, "Social Desirability and Response Valitdity: A Comparative Analysis of Over-reporting Voter Turnout in Five Countries," Journal of Politics, Vol. 67 no.3, pp. 825-840.

Kleitz, B., G.R. Weiher, K. Tedin, and R. Matland "Choices, Charter Schools and Household Preferences” Social Science Quarterly (1998) Vol. 81, No. 3, pp. 846854.

Manski, Charles F. and David A. Wise College Choice in America (Cambridge, MA: Harvard University Press, 1983).

McFadden, D. and K. Train (2000). "Mixed Multinomial Logit Models for Discrete Response.” Journal of Applied Econometrics, 15(5): 447-470.

Neal, Derek "How Vouchers Could Change the Market for Education,” Journal of Economic Perspectives, Vol (16) no. 4, pp.25-44, Fall (2002).

Nechyba, Thomas (1999), "School Finance Induced Migration Patterns: The Impact of Private School Vouchers.” Journal of Public Economic Theory. Vol(1):1, pp.5-50.

Nechyba, Thomas (2000), “Mobility, Targeting and Private School Voucher,” American Economic Review. Vol (90) no.1, pp.130-146.

Nechyba, Thomas (2003), "School Finance, Spatial Income Segregation and the Nature of Communities," Journal of Urban Economics 54(1), 61-88.

Roth, Alvin E. and I Erev, "Learning in Extensive Form Games: Experimental Data and Simple Dynamic Models in the Intermediate Term," Games and Economic Behavior, Special Issue: Nobel Symposium, Vol. 8, January (1995), pp.164-212.

Schneider, M., M. Marschall, P. Teske and C. Roch "School Choice and Culture Wars in the Classroom: What Different Parents Seek from Education” Social Science Quarterly (1998) Vol 79, No. 3, pp. 489-501.

Train, Kenneth E. Discrete Choice Methods with Simulation. Cambridge University Press (2003).

Vanourek, G., B.V. Manno, and C.E. Finn, “Charter Schools as Seen by Students, Teachers and Parents" in Paul Peterson and Bryan Hassel (eds.) Learning from School Choice. (Washington, DC: Brookings Institution Press, 1998). 
Table I: Summary Statistics of Students and Choices

\begin{tabular}{|lcccc|}
\hline & \multicolumn{2}{c}{$\begin{array}{c}\text { Not Receiving } \\
\text { Lunch Subsidies }\end{array}$} & \multicolumn{2}{c|}{$\begin{array}{c}\text { Receiving Lunch } \\
\text { Subsidies }\end{array}$} \\
& White & Black & White & Black \\
\hline \hline Student Characteristics & & & & \\
$\quad$ Average Test score & 0.6384 & -0.0905 & -0.0851 & -0.6128 \\
$\quad$ (St. Dev.) & $(0.8249)$ & $(0.8395)$ & $(0.8480)$ & $(0.7996)$ \\
$\quad$ Neighborhood Income & 73,812 & 50,635 & 52,734 & 36,459 \\
$\quad$ (St. Dev.) & $(25,866)$ & $(21,506)$ & $(22,329)$ & $(16,241)$ \\
& & & & \\
Choice Characteristics & & & & \\
$\quad$ Percent Listed 1st Choice Only & 0.5123 & 0.2768 & 0.3311 & 0.2065 \\
$\quad$ Percent Listed 2 Choices & 0.1985 & 0.1778 & 0.2057 & 0.1664 \\
Percent Listed 3 Choices & 0.2892 & 0.5454 & 0.4631 & 0.6271 \\
$\quad$ Percent Chose Home School 1st & 0.6443 & 0.4251 & 0.514 & 0.3827 \\
& & & & \\
Student-Choice Characteristics & & & & \\
$\quad$ Home School Average Test Score & 0.2131 & -0.1864 & -0.1711 & -0.3919 \\
$\quad$ (St. Dev.) & $(0.4035)$ & $(0.3613)$ & $(0.3739)$ & $(0.3247)$ \\
$\quad$ Distance to Nearest School in the & 2.5664 & 2.6616 & 2.4523 & 2.1272 \\
$\quad$ Top Quartile & $(1.6134)$ & $(1.4828)$ & $(1.4359)$ & $(1.2000)$ \\
$\quad$ (St. Dev.) & & & &
\end{tabular}


Figure 1a: Thematic Map of Charlotte Mecklenburg County with Census Block Groups by Race and School Location by Average Test Score

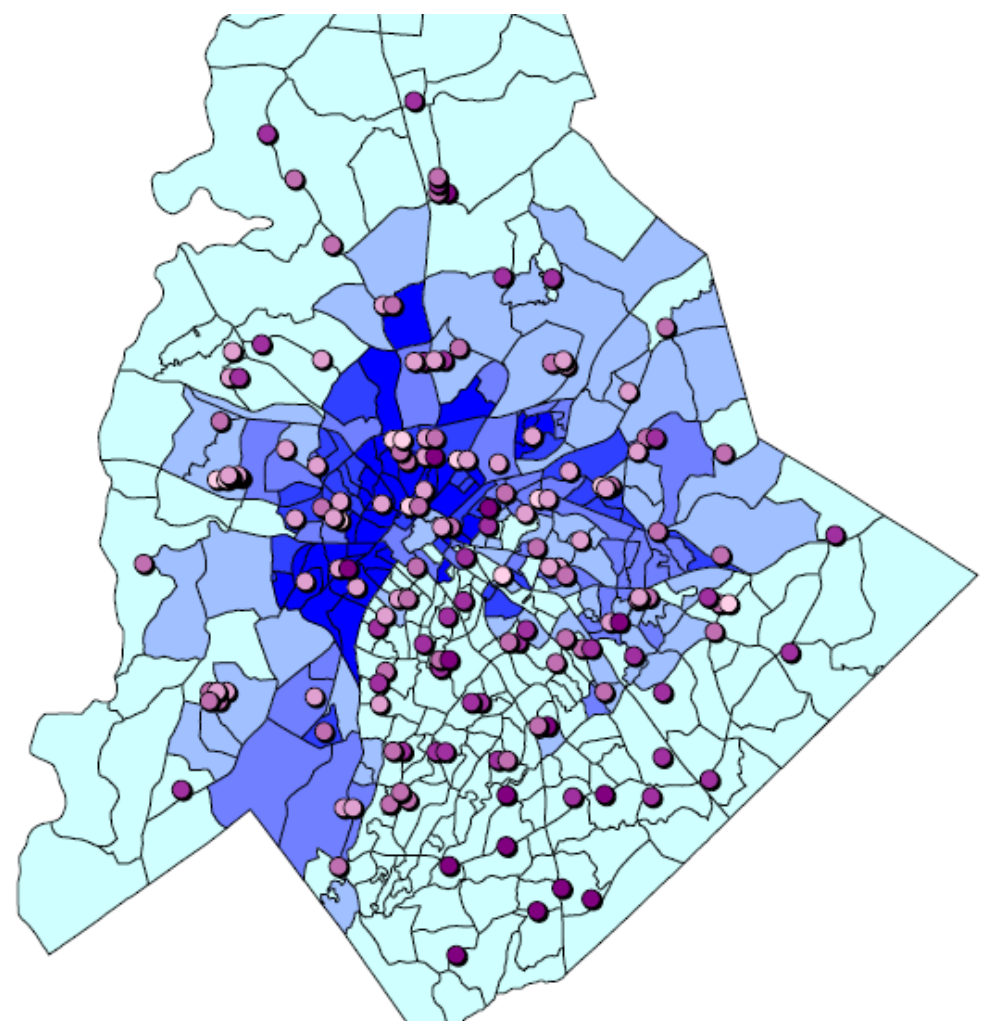

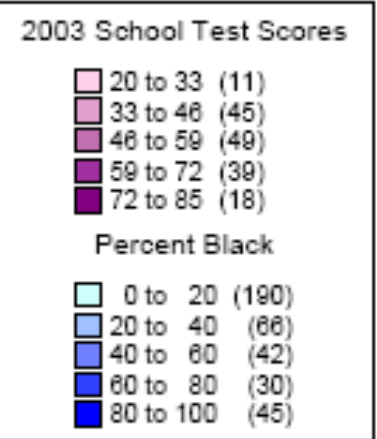

Figure 1b: Close View of Block Groups and School Choices by Average Test Score

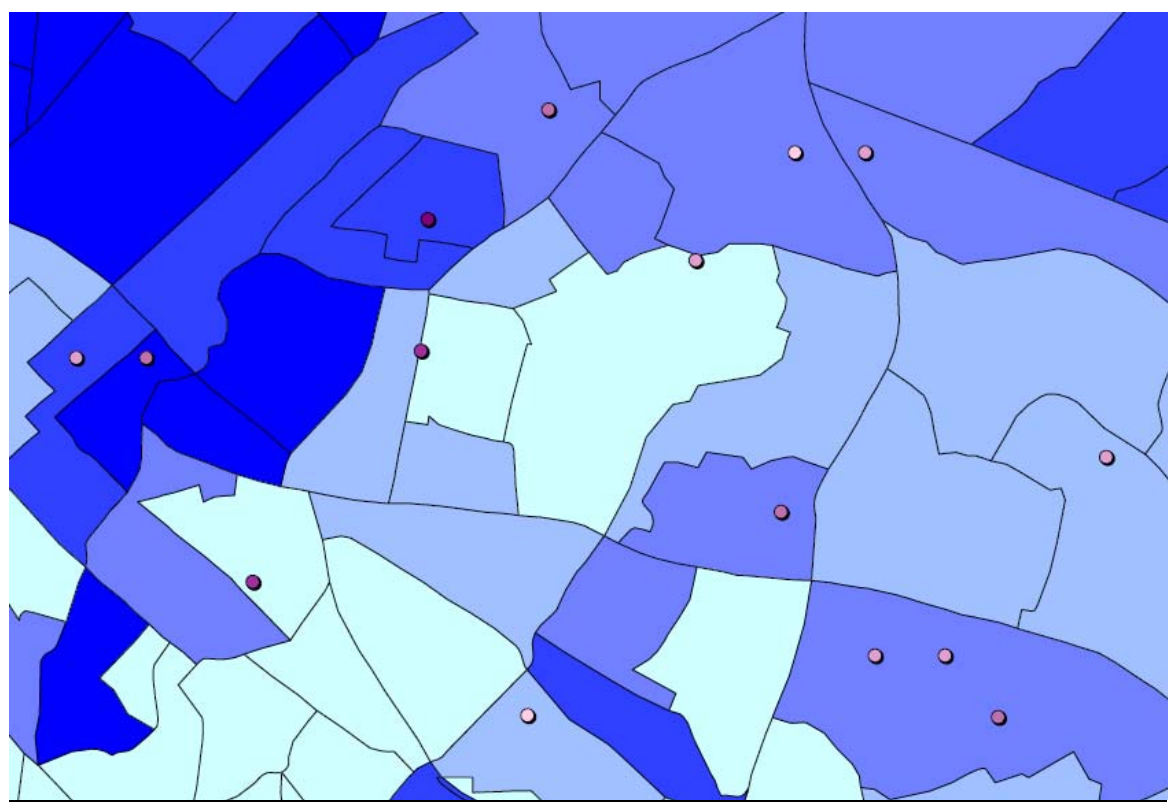


Table II: Explanatory Variable Definitions

\begin{tabular}{|c|c|}
\hline Variable & Description \\
\hline Distance & $\begin{array}{l}\text { Driving distance from student } i \text { to school } j \text { calculated using } \\
\text { MapInfo with Census Tiger Line files. }\end{array}$ \\
\hline School Score & $\begin{array}{l}\text { Average of the 2001-2002 student-level standardized scale score } \\
\text { for End of Grade Math and Reading exams for students in school } \\
j \text { in the } 2002-2003 \text { school year. This is the average test score } \\
\text { variable described below across all students in school } j \text {. }\end{array}$ \\
\hline Test Score & $\begin{array}{l}\text { The sum of student } i \text { 's scale score on End of Grade math and } \\
\text { reading exams in baseline year 2001-2002 standardized by the } \\
\text { mean and standard deviation of district-wide scores for students } \\
\text { in his or her grade. }\end{array}$ \\
\hline Income & $\begin{array}{l}\text { The median household income reported in the } 2000 \text { Census for } \\
\text { households of student i's race in student i's block group. Income } \\
\text { is demeaned by the county-wide average of approximately } \\
\$ 51,000 \text { and is reported in thousands of dollars. }\end{array}$ \\
\hline Percent Black & $\begin{array}{l}\text { The percent of students in school } j \text { who are black according to } \\
\text { 2002-2003 school year administrative data. }\end{array}$ \\
\hline
\end{tabular}

Table III: Explanatory Variable Summary Statistics

\begin{tabular}{|lrrrrr|}
\hline \multicolumn{2}{l}{ Summary Statistics Using First Choice Data } \\
\hline \hline Variable & Obs. & \multicolumn{1}{l|}{ Mean } & \multicolumn{1}{l|}{ Std. Dev. } & \multicolumn{1}{l|}{ Min } & \multicolumn{1}{l|}{ Max } \\
Distance & 2342254 & 13.0151 & 6.7548 & 0.0010 & 42.4069 \\
Last-year School & 2342254 & 0.0149 & 0.1213 & 0.0000 & 1.0000 \\
School Score & 2342254 & -0.1120 & 0.4531 & -0.9427 & 1.9410 \\
Test score & 2342254 & 0.0559 & 0.9885 & -2.9113 & 3.0255 \\
Test score*School-Score & 2342254 & -0.0035 & 0.4633 & -2.7013 & 5.8724 \\
Income & 2342254 & 5.0913 & 27.5661 & -48.5010 & 149.0010 \\
Income*School-Score & 2342254 & -0.5635 & 13.0757 & -140.4703 & 251.7595 \\
Percent Black & 2342254 & 0.5279 & 0.2515 & 0.0584 & 0.9801 \\
\hline
\end{tabular}


Table IV: Estimates from Mixed Logit Model

\begin{tabular}{|c|c|c|c|c|c|}
\hline \multirow{3}{*}{\begin{tabular}{|l} 
\\
Variable
\end{tabular}} & \multirow[b]{3}{*}{$\begin{array}{l}\text { Preference } \\
\text { Parameter }\end{array}$} & \multicolumn{4}{|c|}{ Parameter Estimates* } \\
\hline & & \multicolumn{2}{|c|}{$\begin{array}{c}\text { Not Receiving Lunch } \\
\text { Subsidies }\end{array}$} & \multicolumn{2}{|c|}{$\begin{array}{l}\text { Receiving Lunch } \\
\text { Subsidies }\end{array}$} \\
\hline & & White & Black & White & Black \\
\hline Distance $^{* *}$ & $\begin{array}{l}\text { Mean (lognormal) } \\
\text { Std. Dev. } \\
\text { (loanormal) }\end{array}$ & -0.3464 & -0.2707 & -0.3655 & -0.2814 \\
\hline \multicolumn{6}{|l|}{ Last-year } \\
\hline School & $\begin{array}{l}\text { Mean } \\
\text { Std. Dev. }\end{array}$ & $\begin{array}{l}3.8770 \\
2.5569\end{array}$ & $\begin{array}{l}3.5848 \\
2.9919\end{array}$ & $\begin{array}{l}3.5790 \\
3.4261\end{array}$ & $\begin{array}{l}2.9589 \\
3.5589\end{array}$ \\
\hline Home School & $\begin{array}{l}\text { Mean } \\
\text { Std. Dev. }\end{array}$ & $\begin{array}{r}2.0558 \\
-0.8081\end{array}$ & $\begin{array}{l}1.7103 \\
0.0691\end{array}$ & $\begin{array}{r}1.9302 \\
-0.7966\end{array}$ & $\begin{array}{r}1.7441 \\
-1.2545\end{array}$ \\
\hline Choice Zone & $\begin{array}{l}\text { Mean } \\
\text { Std. Dev. }\end{array}$ & $\begin{array}{l}1.2648 \\
0.8838\end{array}$ & $\begin{array}{l}1.3015 \\
1.2214\end{array}$ & $\begin{array}{l}1.9021 \\
1.4936\end{array}$ & $\begin{array}{l}1.5866 \\
1.2084\end{array}$ \\
\hline School Score & $\begin{array}{l}\text { Mean } \\
\text { Std. Dev. }\end{array}$ & $\begin{array}{l}1.6627 \\
0.2530\end{array}$ & $\begin{array}{l}2.3404 \\
0.2810\end{array}$ & $\begin{array}{l}0.6504 \\
0.6478\end{array}$ & $\begin{array}{l}1.2669 \\
0.3474\end{array}$ \\
\hline $\begin{array}{l}\text { Test score * } \\
\text { School Score }\end{array}$ & Mean & 0.4752 & 0.3981 & 0.2888 & 0.3438 \\
\hline \multicolumn{6}{|l|}{ Income*School } \\
\hline Score & $\begin{array}{l}\text { Mean } \\
\text { Std. Dev. }\end{array}$ & $\begin{array}{l}0.0139 \\
--\end{array}$ & $\begin{array}{l}0.0139 \\
--\end{array}$ & $\begin{array}{l}-- \\
--\end{array}$ & $\begin{array}{l}-- \\
--\end{array}$ \\
\hline Percent Black & $\begin{array}{l}\text { Mean } \\
\text { Std. Dev. }\end{array}$ & $\begin{array}{l}3.7166 \\
2.8234\end{array}$ & $\begin{array}{l}5.8296 \\
1.8174\end{array}$ & $\begin{array}{l}2.3117 \\
2.2885\end{array}$ & $\begin{array}{l}3.4708 \\
1.1362\end{array}$ \\
\hline $\begin{array}{l}\text { Percent Black } \\
\text { Squared }\end{array}$ & $\begin{array}{l}\text { Mean } \\
\text { Std. Dev. }\end{array}$ & $\begin{array}{l}-5.2588 \\
--\end{array}$ & $\begin{array}{l}-3.6604 \\
--\end{array}$ & $\begin{array}{l}-3.6392 \\
--\end{array}$ & $\begin{array}{l}-2.2540 \\
--\end{array}$ \\
\hline \multicolumn{2}{|c|}{ Implied Mean Preferred \% Black } & 0.3534 & 0.7963 & 0.3176 & 0.7699 \\
\hline & Std. Dev. & 0.2684 & 0.2483 & 0.3144 & 0.2520 \\
\hline \multicolumn{6}{|c|}{ Estimated Correlation Coefficients: } \\
\hline \multicolumn{2}{|c|}{ Corr(Distance, School Score) } & 0.5808 & -0.3273 & 0.4585 & -0.6747 \\
\hline \multicolumn{2}{|c|}{ Corr(Distance, Home School) } & 0.1041 & 0.0006 & -0.1935 & -0.1061 \\
\hline \multicolumn{2}{|c|}{ Corr(School Score, Home School) } & -0.1727 & -0.9424 & -0.8235 & -0.3731 \\
\hline
\end{tabular}

* All estimates are significant at the $1 \%$ level or higher

** Distribution of preference on distance follows a log normal distribution. 
Table V: Comparing Alternative Measures of School Academic Achievement

\begin{tabular}{|c|c|c|c|c|c|}
\hline & \multirow[b]{2}{*}{$\begin{array}{l}\text { Preference } \\
\text { Parameter }\end{array}$} & \multicolumn{2}{|c|}{$\begin{array}{l}\text { Not Receiving Lunch } \\
\text { Subsidies }\end{array}$} & \multicolumn{2}{|c|}{$\begin{array}{l}\text { Receiving Lunch } \\
\text { Subsidies }\end{array}$} \\
\hline & & White & Black & White & Black \\
\hline \multicolumn{6}{|c|}{$\begin{array}{l}\text { Score Measure: Spring } 2002 \text { scores of student in school in Spring } \\
2003\end{array}$} \\
\hline - log likelihood & & 41311.12 & 32954.29 & 9241.04 & 80209.13 \\
\hline \multirow[t]{2}{*}{ School Score } & Mean & 1.6627 & 2.3404 & 0.6504 & $1.266 \mathrm{~s}$ \\
\hline & St. Dev. & 0.2530 & 0.2810 & 0.6478 & 0.3474 \\
\hline $\begin{array}{l}\text { Test score * School } \\
\text { Score }\end{array}$ & Mean & 0.4752 & 0.3981 & 0.2888 & 0.3438 \\
\hline Income $^{*}$ School Score & $\begin{array}{l}\text { St. Dev. } \\
\text { Mean }\end{array}$ & -0.0139 & 0.0139 & $\begin{array}{l}-- \\
--\end{array}$ & -- \\
\hline \multicolumn{6}{|c|}{$\begin{array}{l}\text { Score Measure: Spring } 2003 \text { scores of student in school in Spring } \\
2003\end{array}$} \\
\hline \multirow{3}{*}{$\begin{array}{l}\text { - log likelihood } \\
\text { School Score }\end{array}$} & & 41458.57 & 33201.53 & 9246.13 & 80402.94 \\
\hline & Mean & 1.3855 & 1.9640 & 0.5656 & 1.0616 \\
\hline & St. Dev. & 0.4259 & 0.2421 & 0.6985 & 0.3867 \\
\hline \multirow[t]{2}{*}{$\begin{array}{l}\text { Test score * School } \\
\text { Score }\end{array}$} & Mean & 0.4852 & 0.4415 & 0.2763 & 0.3233 \\
\hline & St. Dev. & -- & -- & -- & -- \\
\hline \multirow[t]{2}{*}{ Income* School Score } & Mean & 0.0136 & 0.0119 & -- & -- \\
\hline & St. Dev. & -- & -- & -- & -- \\
\hline \multicolumn{6}{|c|}{$\begin{array}{l}\text { Score Measure: Spring } 2002 \text { scores of student in school in Spring } \\
2002\end{array}$} \\
\hline - log likelihood & & 41809.18 & 33758.23 & 9306.37 & 80777.08 \\
\hline \multirow{2}{*}{ School Score } & Mean & 0.9107 & 1.0208 & 0.4068 & 0.4837 \\
\hline & St. Dev. & 0.5060 & 0.0914 & 0.6163 & 0.4471 \\
\hline \multirow{2}{*}{$\begin{array}{l}\text { Test score * School } \\
\text { Score }\end{array}$} & Mean & 0.4824 & 0.4586 & 0.2641 & 0.3057 \\
\hline & St. Dev. & -- & -- & -- & -- \\
\hline \multirow[t]{2}{*}{ Income* School Score } & Mean & 0.0096 & 0.0085 & -- & -- \\
\hline & St. Dev. & -- & -- & -- & -- \\
\hline \multicolumn{6}{|c|}{ Value Added: Average regression adjusted gains in test scores from 2002-2003* } \\
\hline - log likelihood & & 42452.06 & 34120.71 & 9286.52 & 80858.73 \\
\hline \multirow[t]{2}{*}{ School Score } & Mean & -1.0668 & -0.5114 & -0.7711 & -0.7896 \\
\hline & St. Dev. & 1.4638 & 0.5670 & 0.9681 & 0.8189 \\
\hline \multirow[t]{2}{*}{$\begin{array}{l}\text { Test score * School } \\
\text { Score }\end{array}$} & Mean & 1.5659 & 1.3402 & 0.2098 & 0.2062 \\
\hline & & -- & -- & -- & -- \\
\hline \multirow[t]{2}{*}{ Income* School Score } & Mean & 0.0161 & -0.0047 & -- & -- \\
\hline & St. Dev. & -- & -- & -- & -- \\
\hline
\end{tabular}

*Value Added calculated as school fixed effects in a regression of 2003 standardized test scores on 2002 standardized scores, controlling for student characteristics such as race, lunch recipient status and grade level. Empirical Bayes measures of Value added were calculated and were correlated with Value-added 0.95. 
Table VI: Differences in Scores Across Redistricted Polygons Average Difference in 2002-2003 Home School Scores within a Given 2001-2002 School Assignment Polygon

\begin{tabular}{|llcc|}
\hline \hline & & Mean & Stdev \\
Not Receiving & White & 0.2925 & 0.3165 \\
Lunch Subsidies & Not white & 0.2570 & 0.2552 \\
Receiving Lunch & White & 0.2891 & 0.2836 \\
Subsidies & Not white & 0.2866 & 0.3111 \\
\hline
\end{tabular}

Table VII: Seemingly Unrelated Regression Conditional Logit Estimates of Preferences for Academics Across Redistricting Winners and Losers

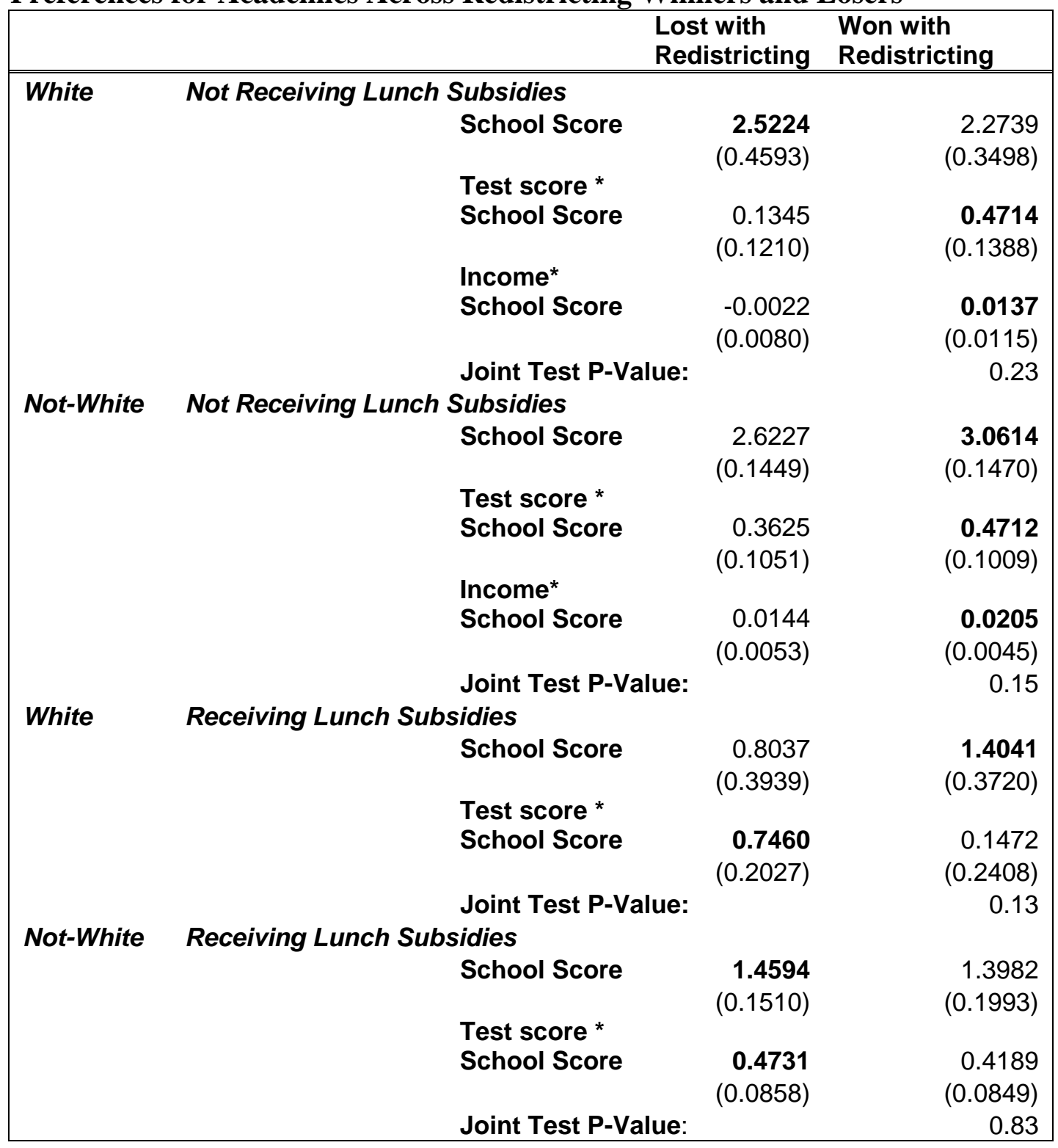


Table VIII: Summary Statistics Comparing Redistricted and Non Redistricted Students

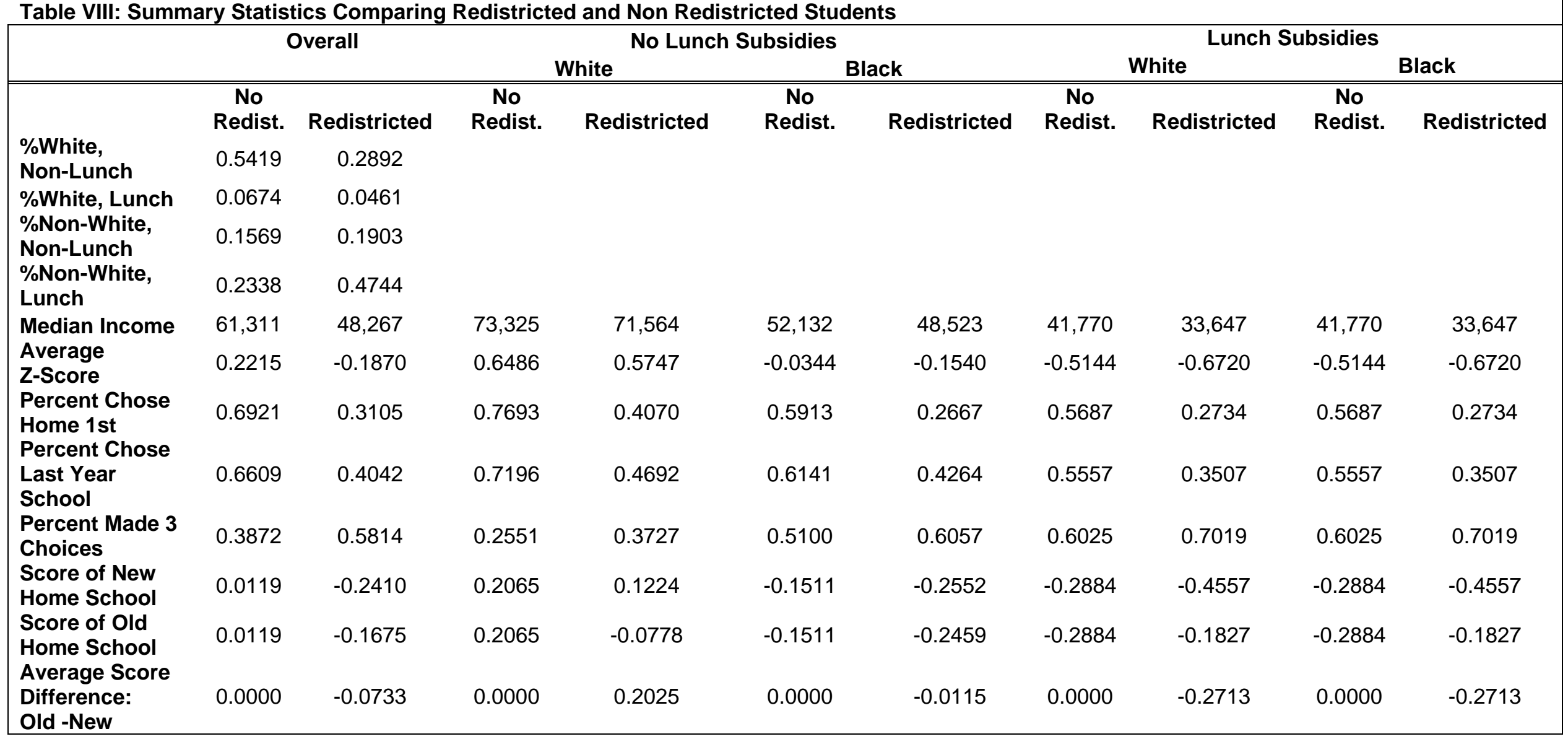


Table IX: Mixed Logit Estimates for Redistricted Sub-sample of Students

\begin{tabular}{|c|c|c|c|c|c|}
\hline \multirow{3}{*}{$\begin{array}{l}\text { Variable } \\
\end{array}$} & \multirow[b]{3}{*}{$\begin{array}{l}\text { Preference } \\
\text { Parameter }\end{array}$} & \multicolumn{4}{|c|}{ Parameter Estimates* } \\
\hline & & \multicolumn{2}{|c|}{$\begin{array}{l}\text { No Lunch } \\
\text { Subsidies }\end{array}$} & \multicolumn{2}{|c|}{$\begin{array}{l}\text { Lunch } \\
\text { Subsidies }\end{array}$} \\
\hline & & White & Black & White & Black \\
\hline \multirow[t]{2}{*}{ Distance $^{\star \star}$} & $\begin{array}{l}\text { Mean (lognormal) } \\
\text { Std. Dev. }\end{array}$ & -0.3763 & -0.2745 & -0.3061 & -0.2801 \\
\hline & (lognormal) & 0.0661 & 0.0408 & 0.0395 & 0.0589 \\
\hline \multirow{2}{*}{$\begin{array}{l}\text { Last-year } \\
\text { School }\end{array}$} & Mean & 3.5422 & 3.4251 & 3.5870 & 3.0111 \\
\hline & Std. Dev. & 2.3087 & 2.8449 & 2.8059 & 3.4437 \\
\hline \multirow[t]{2}{*}{ Home School } & Mean & 2.3071 & 1.8390 & 2.0496 & 1.8338 \\
\hline & Std. Dev. & 0.8174 & 1.1331 & 1.5804 & 1.5533 \\
\hline \multirow[t]{2}{*}{ Choice Zone } & Mean & 1.1425 & 1.3133 & 1.7984 & 1.6011 \\
\hline & Std. Dev. & 0.7629 & 1.0372 & 1.2424 & 0.9999 \\
\hline \multirow[t]{2}{*}{ School Score } & Mean & 1.5587 & 2.4388 & 0.3785 & 1.1470 \\
\hline & Std. Dev. & 0.4442 & 0.5068 & 0.4040 & 0.6688 \\
\hline $\begin{array}{l}\text { Test score * } \\
\text { School Score }\end{array}$ & $\begin{array}{l}\text { Mean } \\
\text { Std. Dev. }\end{array}$ & $\begin{array}{l}0.5371 \\
--\end{array}$ & $\begin{array}{l}0.4270 \\
--\end{array}$ & $\begin{array}{l}0.0928 \\
--\end{array}$ & $\begin{array}{l}0.3071 \\
--\end{array}$ \\
\hline \multirow{2}{*}{$\begin{array}{l}\text { Income*School } \\
\text { Score }\end{array}$} & Mean & 0.0196 & 0.0197 & -- & -- \\
\hline & Std. Dev. & -0190 & -- & -- & -- \\
\hline \multirow[t]{2}{*}{ Percent Black } & Mean & 3.5729 & 5.5543 & 0.9015 & 2.3149 \\
\hline & Std. Dev. & 2.8769 & 1.8569 & 1.8622 & 0.7953 \\
\hline \multirow{2}{*}{$\begin{array}{l}\text { Percent Black } \\
\text { Squared }\end{array}$} & Mean & -5.2151 & -3.4869 & -2.5284 & -1.4146 \\
\hline & Std. Dev. & -- & -- & -- & -- \\
\hline \multirow{2}{*}{\multicolumn{2}{|c|}{$\begin{array}{c}\text { Implied Mean Preferred \% Black } \\
\text { Std. Dev. }\end{array}$}} & 0.3426 & 0.7965 & 0.1783 & 0.8182 \\
\hline & & 0.2758 & 0.2663 & 0.3683 & 0.2811 \\
\hline \multicolumn{6}{|c|}{ Estimated Correlation Coefficients: } \\
\hline \multirow{2}{*}{\multicolumn{2}{|c|}{$\begin{array}{l}\text { Corr(Distance, School Score) } \\
\text { Corr(Distance, Home School) }\end{array}$}} & 0.3951 & -0.3571 & 0.5111 & -0.6070 \\
\hline & & 0.1344 & -0.0063 & -0.1847 & -0.1083 \\
\hline \multicolumn{2}{|c|}{ Corr(School Score, Home School) } & -0.6297 & -0.7740 & -0.7727 & -0.4230 \\
\hline
\end{tabular}

* All estimates are significant at the $1 \%$ level or higher

** Distribution of preference on distance follows a log normal distribution. 
Figure 2a: Elementary Schools: Simulated Change in Number of Students Choosing School $j$ when the Average Standardized Score at School $j$ increase by 0.33 points.

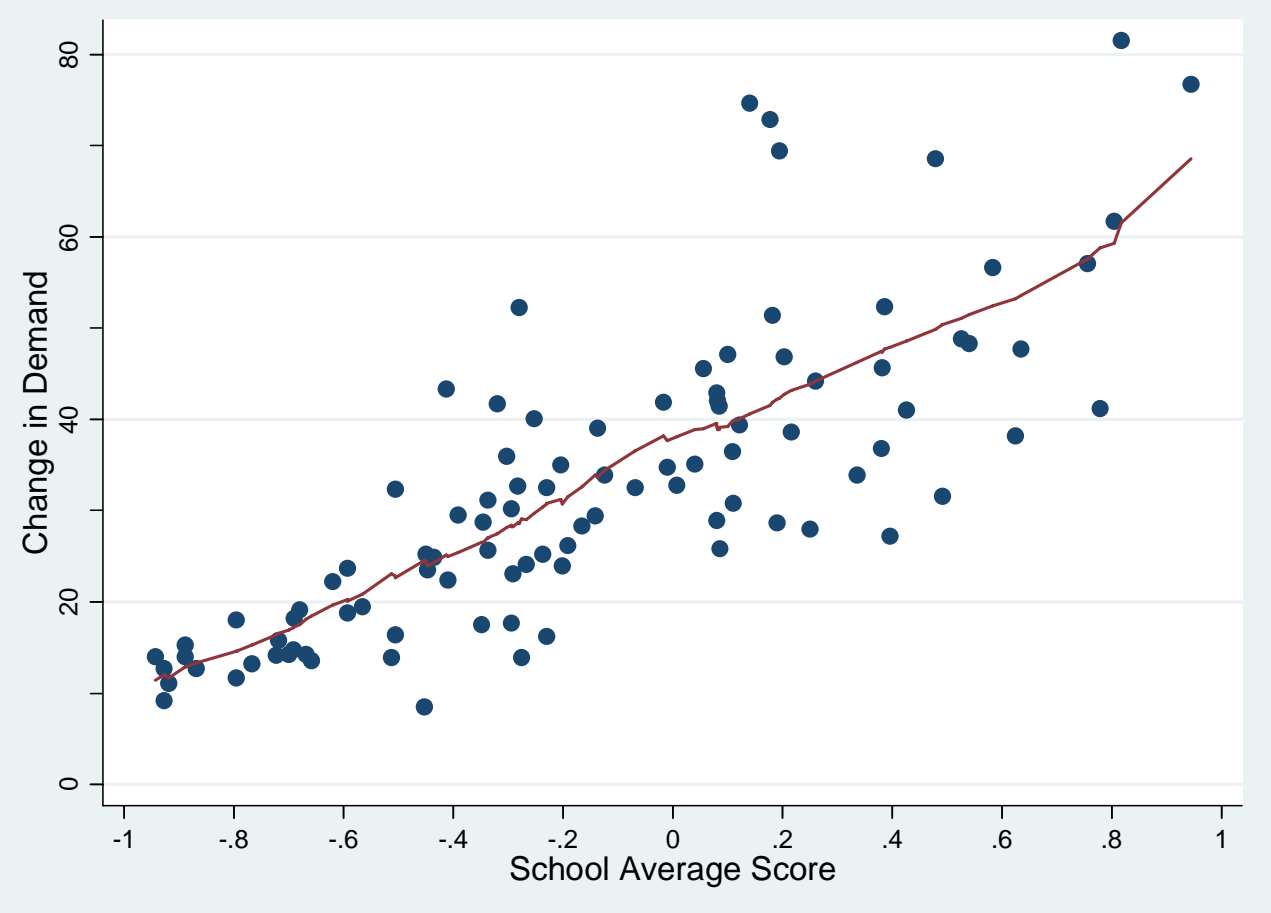

Figure 2b: Middle Schools: Simulated Change in Number of Students Choosing School $j$ when the Average Standardized Score at School $j$ increase by 0.33 points

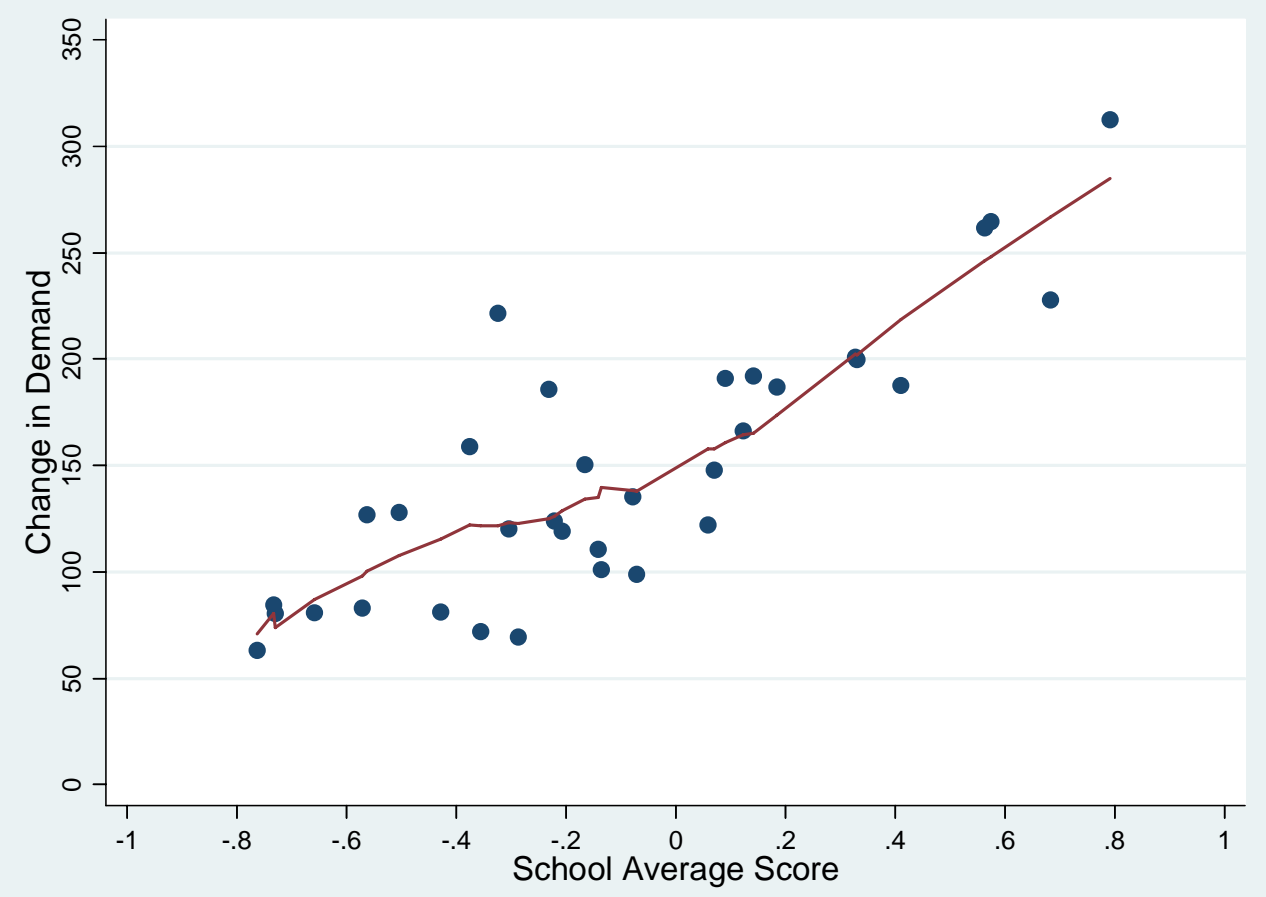


Figure 3: Percent of the Additional Students who Choose School $j$ in Response to a 0.33 point Increase in Standardized Percentile Score at School $j$ who qualify for Free Lunch.

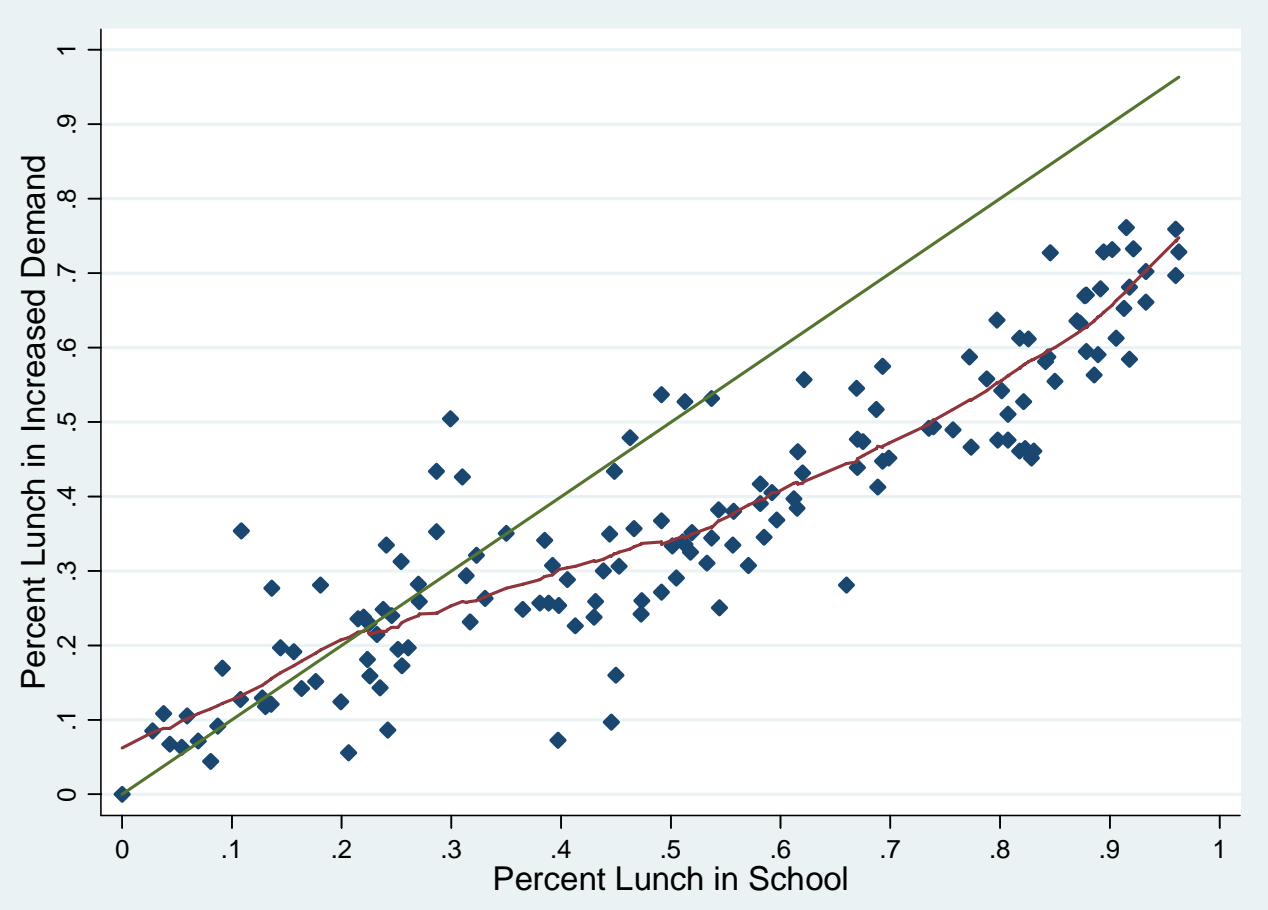

Figure 4: Average 2002 St.Dev Scale Score for the Additional Students who Choose School $\boldsymbol{j}$ in Response to a 0.33 point Increase in Ave. Score at School $\boldsymbol{j}$.

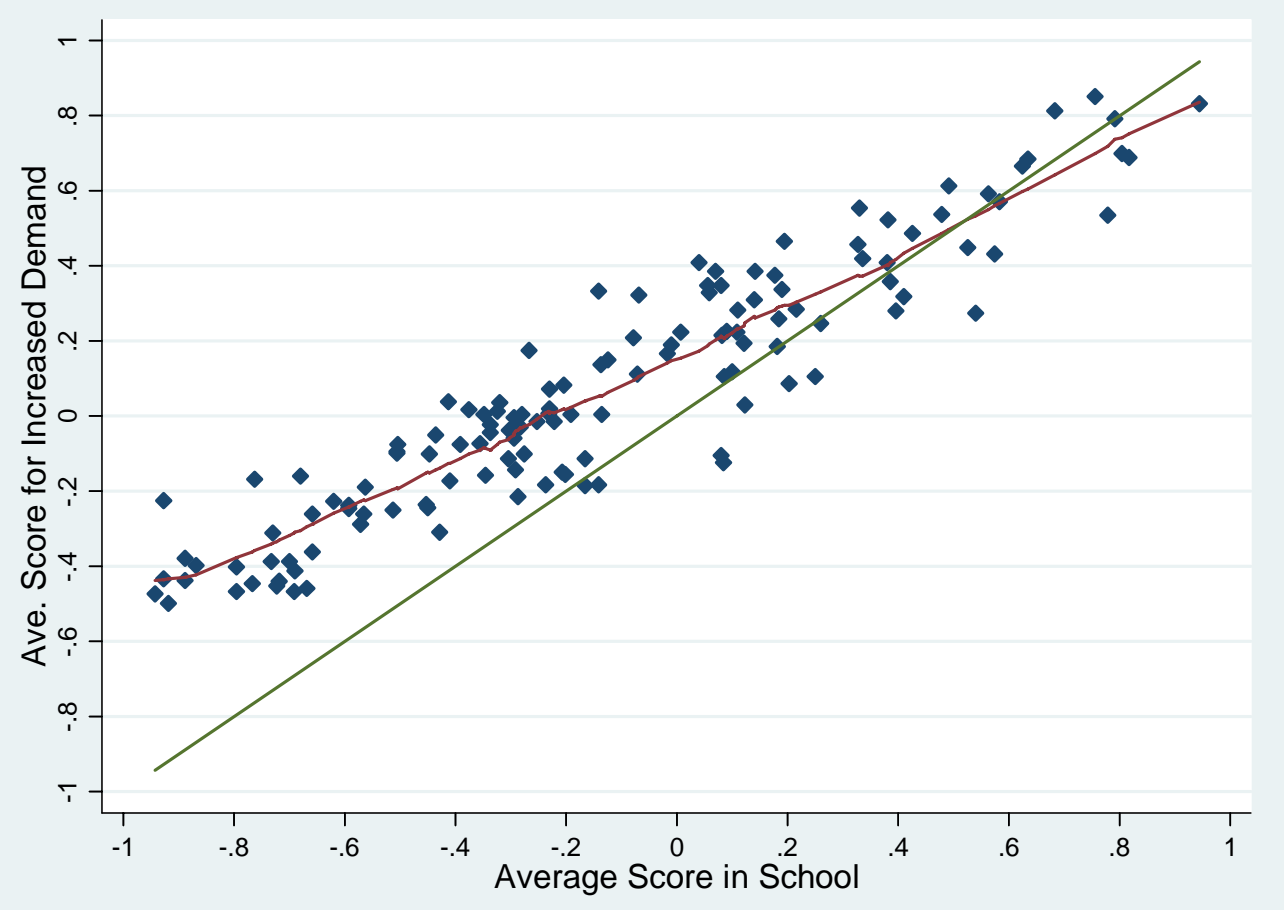




\section{APPENDIX TABLES:}

Table A.I: Standard Errors for Parameter Estimates in Table IV

\begin{tabular}{|lllll|}
\hline & \multicolumn{2}{l}{ No Lunch Subsidies } & \multicolumn{2}{l|}{ Lunch Subsidies } \\
& White & Black & White & Black \\
\hline \hline Standard Errors on Mean Preferences & & & & \\
Distance & 0.0002485 & 0.0000020 & 0.0000055 & 0.0000021 \\
Last-year School & 0.0003436 & 0.0000015 & 0.0000059 & 0.0000291 \\
Home School & 0.0002006 & 0.0000394 & 0.0000194 & 0.0000280 \\
Choice Zone & 0.0006687 & 0.0000019 & 0.0000040 & 0.0000211 \\
School Score & 0.0012939 & 0.0000888 & 0.0000192 & 0.0000704 \\
Test Score * School Score & 0.0004424 & 0.0000018 & 0.0000190 & 0.0000543 \\
Income*School Score & 0.0000521 & 0.0000003 & -- & -- \\
Percent Black & 0.0357668 & 0.0002074 & 0.0003098 & 0.0007694 \\
Percent Black Squared & 0.0378734 & 0.0000378 & 0.0002692 & 0.0006274 \\
& & & & \\
Standard Errors on Standard Deviations & & & & \\
Distance & 0.0000359 & 0.0000093 & 0.0000049 & 0.0000005 \\
Last-year School & 0.0001151 & 0.0001092 & 0.0000413 & 0.0000178 \\
Home School & 0.0004402 & 0.0000702 & 0.0000112 & 0.0000530 \\
Choice Zone & 0.0023968 & 0.0000583 & 0.0000124 & 0.0000459 \\
School Score & 0.0008831 & 0.0000249 & 0.0000140 & 0.0000272 \\
Percent Black & 0.0084486 & 0.0000289 & 0.0001043 & 0.0002395 \\
& & & & \\
Corr(Dist., Score) & 0.0000613 & 0.0003647 & 0.0000121 & 0.0002664 \\
Corr(Dist., Home Schl.) & 0.0000817 & 0.0001029 & 0.0000046 & 0.0000073 \\
Corr(Score, Home Schl.) & 0.0051998 & 0.0000999 & 0.0000125 & 0.0001219 \\
\hline
\end{tabular}

